\title{
THE IMPACT OF CLIMATE CHANGE ON LIVESTOCK MANAGEMENT IN AFRICA: A STRUCTURAL RICARDIAN ANALYSIS ${ }^{1}$
}

\section{Sungno Niggol Seo and Robert Mendelsohn²}

\section{World Bank Policy Research Working Paper 4279, July 2007}

The Policy Research Working Paper Series disseminates the findings of work in progress to encourage the exchange of ideas about development issues. An objective of the series is to get the findings out quickly, even if the presentations are less than fully polished. The papers carry the names of the authors and should be cited accordingly. The findings, interpretations, and conclusions expressed in this paper are entirely those of the authors. They do not necessarily represent the view of the World Bank, its Executive Directors, or the countries they represent. Policy Research Working Papers are available online at http://econ.worldbank.org.

\footnotetext{
${ }^{1}$ An earlier version of this Working Paper was published as CEEPA Discussion Paper number 23.

${ }^{2}$ University of Aberdeen Business School, United Kingdom and School of Forestry and Environmental Studies, Yale University, 230 Prospect Street, New Haven, CT 06511, USA, Seo e-mail: niggol.seo@abdn.ac.uk; Mendelsohn tel: 203-432-5128, e-mail: robert.mendelsohn@yale.edu.

The authors want especially to thank Pradeep Kurukulasuriya, Rashid Hassan, James Benhin, Ariel Dinar, Temesgen Deressa, Mbaye Diop, Helmy Mohamed Eid, K Yerfi Fosu, Glwadys Gbetibouo, Suman Jain, Ali Mahamadou, Reneth Mano, Jane Mariara, Samiha El-Marsafawy, Ernest Molua, Mathieu Ouedraogo, and Isidor Sène.

This paper was funded by the GEF and the World Bank. It is part of a larger study on the effect of climate change on agriculture in Africa, managed by the World Bank and coordinated by the Centre for Environmental Economics and Policy in Africa (CEEPA), University of Pretoria, South Africa.
} 


\section{SUMMARY}

This paper develops the structural Ricardian method, a new approach to modeling agricultural performance using cross-sectional evidence, and uses the method to study animal husbandry in Africa. The traditional Ricardian approach measures the interaction between climate and agriculture (Mendelsohn et al. 1994; Seo et al. 2005) but it does not reveal how farmers actually adapt. It is consequently difficult to compare traditional Ricardian results with microeconomic models built from the details of agronomic research (e.g. Adams et al. 1990, 1999; Reilly et al. 1996). The Model is intended to estimate the structure beneath Ricardian results in order to understand how farmers change their behavior in response to climate. In this African livestock example, the Structural Ricardian Model estimates which species are selected, the number of animals per farm, and the net revenue per animal. All three of these elements are climate sensitive.

A three-equation model is developed to estimate each of the choices facing a farmer. For each farm, a primary animal is defined as the species that is observed to earn the greatest net revenue on that farm. A multinomial logit is then estimated to predict which primary animal each farmer selects. Given the primary animal chosen, the second equation estimates the number of animals of that type per farm. The final equation estimates the net revenue per animal by species.

The model is used to study the sensitivity of African animal husbandry decisions to climate. A survey of over 5000 livestock farmers in ten countries reveals that the selection of species, the net income per animal, and the number of animals are all highly dependent on climate. As climate warms, net income across all animals will fall but especially across beef cattle. The fall in net income causes African farmers to reduce the number of animals on their farms. The fall in relative revenues also causes them to shift away from beef cattle and towards sheep and goats. All farmers will lose income but the most vulnerable farms are large African farms that currently specialize in beef cattle.

Small livestock and large livestock farms respond to climates differently. Small farms are diversified, relying on dairy cattle, goats, sheep and chickens. Large farms specialize in dairy and especially beef cattle. Estimating a separate multinomial logit selection model for small and large farms reveals that the two types of farm choose species differently and specifically have different climate response functions. The regressions of the number of animals also reveal that large farms are more responsive to climate.

Several climate scenarios are tested using the estimated three-equation model. Some simple uniform climate change scenarios are tested that assume a warming of $2.5^{\circ} \mathrm{C}$ or $5^{\circ} \mathrm{C}$ and a change in precipitation of $+15 \%$ or $-15 \%$. The purpose of these scenarios is to see how different districts across Africa respond to identical changes in climate. Uniform warming causes the probability of choosing beef cattle to fall where these are currently being chosen. In contrast, warming causes the probability of choosing sheep to rise, especially across the Sahel. Warming causes the number of animals to fall but especially beef cattle. Finally warming causes the net revenue from all animals to fall, but especially from beef cattle. Increasing precipitation causes the probability of choosing beef cattle, dairy cattle and sheep to fall and that of goats and chickens to increase. Wetter climatic conditions reduce the desired number and net revenue of beef cattle, dairy cattle, 
sheep and chickens, but not goats. This effect is most likely due to the change in landscape, associated with more precipitation, from savanna to forest. Combining all these changes, a $2.5^{\circ} \mathrm{C}$ warming results in a $32 \%$ loss in expected net income and a $5^{\circ} \mathrm{C}$ warming leads to a $70 \%$ loss in expected net income. Increasing precipitation by $15 \%$ results in a $1 \%$ loss in expected net income.

We also examine climate change impacts using the separate regressions for small and large livestock farms. With warming, small farms are expected to shift away from dairy cattle and chickens to goats and sheep. Net incomes will fall for all animals except for sheep. The number of animals will also fall. Expected income will fall by $13 \%$ with a warming of $2.5^{\circ} \mathrm{C}$, but recover with more warming to current levels of income. A $15 \%$ decrease in precipitation is expected to increase small livestock farm incomes by $6 \%$. For large farms, warming will cause a shift to dairy cattle and sheep and away from goats, chickens and especially beef cattle. The income per animal falls for all species as temperatures rise. With higher temperatures, large farms choose to have fewer beef, chickens and sheep and choose more goats and dairy cattle. Large farmers' incomes are expected to fall by an average of $26 \%$ with a $2.5^{\circ} \mathrm{C}$ warming and by $67 \%$ with a $5^{\circ} \mathrm{C}$ warming, but a $15 \%$ decrease in precipitation is expected to increase these farmers' incomes by $2 \%$.

The study also examines the consequences of a range of climate predictions from three Atmospheric Oceanic General Circulation Models (AOGCMs). These models predict that climate change will cause beef cattle to decrease in Africa and sheep and goats to increase. In general, the climate models predict that the overall number of animals will fall although the number of goats may increase. They also predict that the net revenue per animal will fall. Combining all of these effects, the climate models predict average losses of $22 \%$ ( $\$ 8$ to $\$ 23$ billion) in expected net income from livestock by 2020. These damages increase to $31 \%$ ( $\$ 9$ to $\$ 24$ billion) by 2060 , and to $54 \%$ ( $\$ 25$ to $\$ 40$ billion) by 2100 .

Examining the effect on small and large farms reveals that small farms will choose dairy cattle and sheep more often and goats and chickens less often as the primary animal. The income per animal will tend to fall over time except for sheep. The number of animals will tend to fall with warming with a few exceptions. The changes in the number of goats and sheep are relatively negligible. The expected income for small farms will tend to increase over time with the Canadian Climate Center (CCC) scenarios (34\%), but fluctuate with the Parallel Climate Model (PCM) and Center for Climate System Research (CCSR) scenarios depending on precipitation. Large farmers, in contrast, will shift away from beef cattle and chickens in favor of dairy cattle, sheep and goats. Net revenues will fall across animals, but especially for beef cattle. The numbers of beef cattle and chickens will fall by large amounts, but the numbers of goats and sheep will increase depending upon the scenarios. Putting all these results together, CCC will lead to a $\$ 6000$ reduction in expected net revenue per large farm $(77 \%)$, CCSR to a $\$ 2,700$ reduction (34\%), and PCM to a $\$ 3,400$ reduction (43\%) by 2100 .

The results indicate that warming will be harmful to commercial livestock owners, especially cattle owners. Owners of commercial livestock farms have few alternatives either in crops or other animal species. In contrast, small livestock farms are better able to adapt to warming or precipitation increases by switching to heat tolerant animals or crops. Livestock operations will be a safety valve for small farmers if warming or drought causes their crops to fail. 


\section{TABLE OF CONTENTS}

$\begin{array}{lll}\text { Section } & \text { Page }\end{array}$

1 Introduction 5

2 Theory 5

3 Data and empirical specification $\quad 10$

4 Empirical results 10

5 Climate simulations 14

6 Conclusion and policy implications 18

$\begin{array}{ll}\text { References } & 20\end{array}$ 


\section{Introduction}

This paper develops a new empirical approach to studying agriculture, the Structural Ricardian Model, and applies it to studying animal husbandry in Africa. This model, a variation of the Ricardian approach (Mendelsohn et al. 1994), estimates the underlying profit functions of specific animals or crops. The original Ricardian model examined the locus of profit maximizing choices of farmers across all output choices. The Structural Ricardian Model estimates the farmer's selection of the most profitable species, the number of animals chosen, and the conditional net revenue per animal. Besides revealing how net revenue changes with climate, this model also reveals details of how farmers adjust to climate. It explains farmer's choices across animals (or crops) and measures how sensitive each animal (or crop) is to exogenous variables. These animal specific results can be more directly compared to natural science based studies (such as Reilly at al. 1996) and economic production studies of individual crops and animals (such as Adams et al. 1999).

We use this new methodology to study the impact of climate change on animal husbandry in Africa. Early analyses of the effects of climate change predicted extensive damage to the agricultural sector across the globe (Pearce 1996). The bulk of agriculture studies on the effect of climate change have focused on crops. However, a large fraction of agricultural output is from livestock. Almost $80 \%$ of African agricultural land is used for grazing. African farmers depend on livestock for income, food, animal products and insurance. Yet there are very few economic analyses of climatic effects on livestock. An important exception to this gap is the study of the effects of climate change on American livestock (Adams et al. 1999). American livestock appear not to be vulnerable to climate change because they live in protected environments (sheds, barns etc.) and have supplemental feed (e.g. hay and corn). In Africa, by contrast, the bulk of livestock have no protective structures and they graze off the land. There is every reason to expect that African livestock will be sensitive to climate change. This study analyzes the behavior of over 9000 African farmers in ten countries in order to measure the climate sensitivity of African animal husbandry. Of the 9000 farmers interviewed, over 5000 were farming livestock.

The underlying theory of the Structural Ricardian Model is developed in the next section. Section 3 discusses how the data were collected and what variables are available. Section 4 discusses the estimation procedure and the empirical results. Several climate change scenarios are then examined in Section 5. The paper looks at both uniform changes in climate across Africa and climate model predictions. It concludes with a summary of results and policy implications.

\section{Theory}

A farmer's optimization decision can be seen as a simultaneous multiple-stage procedure. The farmer chooses the levels of inputs, the desired number of animals and the species that will yield the highest net profit. Given the profit maximizing inputs from each farmer, one can estimate the loci of profit maximizing choices for each animal across exogenous environmental factors such as temperature or precipitation. These are the individual loci that lie beneath the overall profit function for the farm (Mendelsohn et al. 1994). We call the approach 'structural' because it estimates the underlying profit response functions (the structure) that form the overall Ricardian 
response. For example, in Figure 1 we display a traditional Ricardian response function with respect to temperature. Underneath the loci of all choices is a set of animal specific response functions. Given the climate, the farmer must choose the most profitable animal and also the inputs that will maximize the value of that animal. We examine the individual net revenue functions for each animal (Structural Ricardian Model) as well as the overall net revenue function across all animals (Ricardian Model).

We assume that each farmer makes his animal husbandry decisions to maximize profit. Hence, the probability that an animal is chosen depends on the profitability of that animal or crop. We assume that farmer $i$ 's profit in choosing livestock $j(j=1,2, \ldots, J)$ is

$$
\pi_{i j}=V\left(K_{j}, S_{j}\right)+\varepsilon\left(K_{j}, S_{j}\right)
$$

where $K$ is a vector of exogenous characteristics of the farm and $S$ is a vector of characteristics of farmer $i$. For example, $K$ could include climate, soils and access variables and $\mathrm{S}$ could include the age of the farmer and family size. The profit function is composed of two components: the observable component $V$ and an error term, $\varepsilon$. The error term is unknown to the researcher, but may be known to the farmer. The farmer will choose the livestock that gives him the highest profit. Defining $Z=(K, S)$, the farmer will choose animal $j$ over all other animals $k$ if:

$\pi^{*}\left(Z_{j i}\right)>\pi^{*}\left(Z_{k i}\right)$ for $\forall \mathrm{k} \neq \mathrm{j} .\left[\right.$ or if $\varepsilon\left(Z_{k i}\right)-\varepsilon\left(Z_{j i}\right)<V\left(Z_{j i}\right)-V\left(Z_{k i}\right)$ for $\left.\mathrm{k} \neq \mathrm{j}\right]$

More succinctly, farmer i's problem is:

$$
\arg \max \left[\pi^{*}\left(Z_{1 i}\right), \pi^{*}\left(Z_{2 i}\right), \ldots, \pi^{*}\left(Z_{J i}\right)\right]
$$

The probability $P_{j i}$ for the $j$ th livestock to be chosen is then

$$
P_{j i}=\operatorname{Pr}\left[\varepsilon\left(Z_{k i}\right)-\varepsilon\left(Z_{j i}\right)<V_{j}-V_{k}\right] \forall \mathrm{k} \neq \mathrm{j} \text { where } \mathrm{V}_{\mathrm{j}}=\mathrm{V}\left(\mathrm{Z}_{\mathrm{ji}}\right)
$$


Assuming $\varepsilon$ is independently Gumbel distributed ${ }^{3}$ and $V_{k}=Z_{k i} \gamma_{k}+\alpha_{k}$,

$$
P_{j i}=\frac{e^{Z_{j i} \gamma_{j}}}{\sum_{k=1}^{J} e^{Z_{k i} \gamma_{k}}}
$$

which gives the probability that farmer $i$ will choose livestock $\mathrm{j}$ among $\mathrm{J}$ animals (Chow 1983; McFadden 1981).

The parameters can be estimated by the Maximum Likelihood Method, using an iterative nonlinear optimization technique such as the Newton-Raphson Method. These estimates are CAN (Consistent and Asymptotically Normal) under standard regularity conditions (McFadden 1999).

Note that farmers can choose more than one species of livestock among the five animals in our study. That is, there are many combinations of animals that the farmer could choose. In this analysis, we assume that farmers choose one primary animal from the five animals. A primary animal is defined as the animal that generates the highest total net revenue in the farm (Train 2003). In Africa, $88 \%$ of total livestock net revenue is earned from a primary animal. ${ }^{4}$

Conditional on the livestock species chosen, we then estimate the optimal number of animals per farm and the net revenue per animal. We rely on a two-stage model. In the first stage, we estimate the probability of selecting an animal (equation 5). In the second stage, conditional on the choice of a specific species, we estimate the optimal number of animals and the net revenue per animal. Because the farmer may observe the error term that the researcher cannot observe, one must correct for possible selection bias. That is, a farmer is more likely to choose a crop or animal that is actually more profitable. Since the farmer maximizes net revenue conditional on the choice of that species, the error in the second stage equation may be correlated with the error in the first stage. According to Dubin and McFadden (1984), with the assumption of the following linearity condition: ${ }^{5}$

\footnotetext{
${ }^{3}$ Two common assumptions about the error term are either the Normal or the Gumbel distribution. Normal random variables have the property that any linear combination of normal varieties is normal. The difference between two Gumbel random variables has a logistic distribution, which is similar to the normal, but with larger tails. Thus the choice is somewhat arbitrary with large samples (Greene 1998).

${ }^{4}$ Alternatively, one could model all the possible combinations of animals (McFadden 1999; Train 2003). Another approach is to model the probability that each animal is chosen in a system of equations (Chib \& Greenberg 1998). Exploring these alternative approaches leads to similar results (Seo \& Mendelsohn 2006b).

${ }^{5}$ See Bourguignon et al. (2004) for the details of the selection bias corrections from the multinomial choice. They find that Dubin and McFadden's method is preferable to the most commonly used Lee method, as well as to the Dhal's semi-parametric method in most cases. Monte Carlo experiments also showed that selection bias correction based on the multinomial logit model can provide fairly good correction for the outcome equation even when the IIA hypothesis is violated.
} 
$E\left(u_{j} \mid \varepsilon_{1}, \ldots, \varepsilon_{J}\right)=\sigma_{j} \cdot \sum_{j=1}^{J} r_{j}\left(\varepsilon_{j}-E\left(\varepsilon_{j}\right)\right)$ with $\sum_{\mathrm{j}=1}^{\mathrm{J}} r_{j}=0$

where $u_{j}=$ error from the second stage, $\varepsilon_{j}=$ error from the first stage, $\sigma_{j}=$ standard error from the unconditioned second stage regression, $r_{j}=$ correlation between the first stage error and second stage error, then the conditional profit functions can be consistently estimated as:

$\pi_{j}=x_{j} \beta_{j}+x_{j}^{2} \delta_{j}+\sigma_{j} \cdot \sum_{i \neq j}^{J} r_{i} \cdot\left(\frac{P_{i} \cdot \ln P_{i}}{1-P_{i}}+\ln P_{j}\right)+w_{j}$

where the second term is the correction term and $\mathrm{w}_{\mathrm{j}}$ is the error term.

The optimal number of animals can be estimated in the same manner:

$N_{j}=x_{j} \beta_{j}+x_{j}^{2} \delta_{j}+\sigma_{j} \cdot \sum_{i \neq j}^{J} r_{i} \cdot\left(\frac{P_{i} \cdot \ln P_{i}}{1-P_{i}}+\ln P_{j}\right)+v_{j}$

where the second term is the correction term and $\mathrm{v}_{\mathrm{j}}$ is the error term.

The two stage model is composed of equation (5) and equations (7a) and (7b). Expected net revenue is therefore:

$W_{i}\left(K_{i}, S_{i}\right)=\sum_{j=1}^{J} P_{j}\left(K_{i}, S_{i}\right) \cdot \pi_{j}\left(K_{i}, S_{i}\right) \cdot N_{j} \quad$ for all $\mathrm{j}$.

Because climate is an independent variable in all three terms in (8), the marginal effect on welfare of a change in a climate variable has three components: the effect on the probability of the livestock to be chosen, the direct effect on the conditional profit per animal, and the effect on the conditional number of animals: 
$\frac{\partial W_{j}}{\partial z_{j}}=\frac{\partial P_{j}}{\partial z_{j}} \cdot \pi_{j} \cdot N_{j}+\frac{\partial \pi_{j}}{\partial z_{j}} \cdot P_{j} \cdot N_{j}+\frac{\partial N_{j}}{\partial z_{j}} \cdot P_{j} \cdot \pi_{j}$

where the marginal effect on the probability can be obtained by differentiating (5):

$$
\frac{\partial P_{j}}{\partial z_{j}}=P_{j}\left[\gamma_{j}-\sum_{k=1}^{J} P_{k} \gamma_{k}\right]
$$

and the marginal effect on the net revenue per animal can be obtained by differentiating (7a):

$$
\frac{\partial \pi_{j}}{\partial z_{j}}=\beta_{j}+2 x_{j} \delta_{j}
$$

and the marginal effect on the number of animals per farm can be found by differentiating (7b):

$$
\frac{\partial \pi_{j}}{\partial z_{j}}=\beta_{j}+2 x_{j} \delta_{j}
$$

The change in welfare resulting from a non-marginal change in climate can be computed as the difference in the expected net revenues in two states. Suppose that climate changes from $C_{A}$ to $C_{B}$. Then the change in welfare can be approximated as:

$$
\Delta W_{i}=W_{i}\left(C_{B}\right)-W_{i}\left(C_{A}\right)
$$

The uncertainty surrounding our measure of the welfare change can be described by the $95 \%$ 
confidence interval of the expected climate change impact. In principle, there are two ways to calculate confidence intervals: parametric and non-parametric. It is difficult to calculate the variance of the climate change impact parametrically in this model, because welfare is the product of three predictions. ${ }^{6}$ Uncertainty estimates are provided by bootstrap methods by resampling and calculating the mean and $95 \%$ intervals of the climate change impacts.

\section{Data and empirical specification}

The data this study relies on were part of a larger GEF project to study climate change impacts on agriculture (Dinar et al. 2006). The countries included were Burkina Faso, Cameroon, Egypt, Ethiopia, Ghana, Kenya, Niger, Senegal, South Africa and Zambia. (Zimbabwe had to be dropped from the livestock analysis because of turbulent conditions in that country during the survey.) They were selected as representative of the wide range of climate throughout Africa, and districts within each country were selected to provide a wide range of climatic variation. The original survey interviewed over 9000 farmers from the 11 countries. Within that sample, over 5000 were livestock farmers.

The data include information on livestock production and transactions, livestock product production and transactions, and relevant costs. The data indicate that the five major types of livestock in Africa are beef cattle, dairy cattle, goats, sheep and chickens. Other less frequently recorded animals include breeding bulls, pigs, oxen, camels, ducks, guinea fowl, horses, bees, and doves. The major livestock products sold were milk, meat, eggs, wool and leather. Others included butter, cheese, honey, skins and manure.

Climate data came from two sources: US Defense Department satellites and weather station observations. We relied on satellite temperature observations and interpolated precipitation observations from ground stations (see Kurukulasuriya and Mendelsohn 2006 for a detailed explanation). Soil data were obtained from the FAO digital soil map of the world CD ROM. The soil data were extrapolated to the district level using GIS (Geographical Information System). The data set reports 116 dominant soil types.

\section{Empirical results}

Although there are many varieties of farm animal in Africa, we focused on the five primary ones that generated most of the income from livestock: beef cattle, dairy cattle, goats, sheep and chickens. Altogether these five animals generated $92 \%$ of the total revenue from livestock. We begin with an analysis of all farms. We then examine small and large farms separately.

\footnotetext{
${ }^{6}$ See Seo et al. (2006a) for the parametric calculation of the confidence intervals.
} 


\section{All farms}

We estimated three sets of equations in our first model. The first set of equations determined whether a farmer chooses a particular animal, the second estimated the number of animals a farmer chooses given that he has picked a particular type of animal, and the third estimated the net revenue per animal given that a farmer has chosen that animal. Because the choice of an animal and the net value of each type of animal are linked, we used a selection model (Heckman 1979). We followed McFadden's model of multinomial choice to estimate the probability each animal is chosen. The choice of each type of animal was assumed to be independent of the choice of any other animal. The probability of choosing each animal was assumed to be a function of summer and winter temperature and summer and winter precipitation. Other explanatory variables included a dummy variable for West Africa, a dummy for large farms, and a dummy variable for electricity.

Table 1 shows the results of the multinomial logit regression of the probability of choosing each of the five animals. The base case is a household that chooses chickens. Most of the estimates are very significant. The test of global significance of the model verifies that the model is highly significant. The positive coefficients imply that the probability of choosing the animal increases as the corresponding variable increases. The amount of increase of the probability can be read from the odds ratio. For example, the odds ratio of the electricity dummy for beef cattle is 2.2, which implies that farms with electricity are 2.2 times (odds ratio) more likely to own beef cattle.

The climate variables are mostly significant. The linear term on summer temperature for sheep is negative but the quadratic term is positive. The same is true for winter temperature. The sheep temperature response function is U-shaped. In contrast, for beef cattle, the linear term is positive but the quadratic term is negative in summer temperature. The cattle temperature response function is hill-shaped. The negative coefficients for West Africa for beef cattle and dairy cattle indicate that West African farms are less likely to have cattle. The coefficients are positive for goats and sheep, indicating that West African farms are more likely to choose goats and sheep. One reason why this region is different from the rest of Africa may be livestock diseases such as nagana (trypanosomiasis), also known as sleeping sickness. Thirty percent of Africa's 160 million cattle population are said to be at risk from these diseases. ${ }^{7}$ Large farmers are more likely to choose large animals than chickens. Farms with electricity are more likely to choose beef cattle, dairy cattle, and sheep, but not goats.

Although this is not included in Table 1, we also tested a set of soil variables, a set of household characteristics, a set of labor use variables, and other social statistics such as religions. These variables were dropped since they were not significant.

Figure 2a graphs the relationship between the probability of choosing a species and annual temperature. Note that the mean temperature in sub-Saharan Africa is $22^{\circ} \mathrm{C}$. The probability of choosing beef cattle and dairy cattle decreases rapidly as temperature rises. In contrast, the probability of choosing goats and sheep climbs as temperature rises. With chickens, the estimated probability is hill-shaped, with a maximum at the current mean temperature of Africa. The graph clearly reveals that the choice of animals in Africa today is very temperature sensitive.

\footnotetext{
${ }^{7}$ International Livestock Research Institute website at http://www.ilri.org.
} 
Figure $2 \mathrm{~b}$ displays the estimated relationship between the probability of choosing an animal and annual precipitation. The probability of choosing beef cattle, dairy cattle and sheep all decrease as precipitation increases. More rain increases the probability of disease (Ford and Katondo 1977) and, perhaps more importantly, shifts the ecosystem from savanna to forest (Sankaran et al. 2005). All three of these animals are clearly more productive in grasslands. In contrast to the above results, goats and especially chickens are more likely as rain increases. Goats may be able to forage more successfully in wetter climates.

In the second stage of the analysis, we estimated the conditional net revenue functions. The net revenue per animal for each chosen species was regressed on climate, the West Africa dummy variable, and a livestock product dummy variable. We accounted for selection bias by using the Dubin-McFadden selection bias correction. These conditional net revenue regressions used only annual and not seasonal climate variables. The seasonal climate variables were not statistically significant. The functional form is quadratic in both temperature and precipitation.

Table 2 summarizes the results of the regression of the conditional net revenue per animal. These regressions confirm that the conditional net incomes from the five animals are sensitive to climate. For all the animals except dairy cattle, the linear terms are negative and the quadratic terms are positive, implying a U-shaped response function with respect to both temperature and precipitation. The coefficients on the West African dummy reveal that West African farmers earn relatively less from dairy cattle and relatively more from goats and sheep compared to other farmers. The coefficient of the livestock product dummy suggests that farms that sell products earn more revenue, except for farms with beef cattle.

The selection bias coefficients reveal interactions among the species. If the coefficients are negative, they suggest the two animals would normally compete with each other. If the coefficients are positive, they suggest the two animals are complementary. That is, the more profitable the farm is for one animal, the more likely the farmer will also choose the other animal. For example, in the beef cattle regressions, the coefficient on the selection term for dairy cattle is positive, suggesting the two types of cattle are complementary. In contrast, the coefficient on the selection term for goats and chickens is negative. Farms which find it profitable to farm beef cattle are less likely to select goats and chickens.

Because the quadratic terms make the climate variables difficult to interpret, we present the estimated climate response functions in Figure 3. Figure 3a shows how conditional net income per animal responds to temperature for each of the five species. The conditional net income per animal is generally higher for beef cattle but it decreases rapidly as temperatures rise. Income per animal has a relatively stable hill-shape for dairy cattle with respect to temperatures. The conditional net income per animal for goats, sheep and chickens decreases with temperature, but the slope of the decrease is relatively small compared to cattle. Although the profitability of goats, sheep and chickens all decrease with warming, they become relatively more attractive to African farmers as temperatures rise.

Figure $3 \mathrm{~b}$ shows how conditional net revenue responds to precipitation. The conditional net revenue of beef cattle decreases precipitously the wetter it gets. Sheep conditional net revenue also decreases with precipitation. However, the conditional net revenue of dairy cattle, goats, and chickens do not seem to be affected by precipitation. Again, although increased precipitation in 
general appears to reduce the profitability of African livestock, the relative profitability of dairy cattle, goats, and chickens increases.

We also estimated a third set of regressions that predict the number of animals of the chosen species a farmer has. As reported in Table 3, farms in districts with more pasture chose more beef cattle and sheep per household, but fewer goats and chickens. Farms with electricity owned more animals. The climate variables were often significant, with the exception of dairy cattle. Other than for sheep, temperature responses are hill-shaped. Precipitation response functions are Ushaped except in the case of goats.

In Figures $4 \mathrm{a}$ and $4 \mathrm{~b}$ we present how the estimated numbers of animals change in response to temperature and precipitation. Figure 4a shows that the number of beef cattle decreases sharply as temperature increases while sheep decrease slightly and then increase in number. There are slight increases in the numbers of goats and dairy cattle. Chickens have a hill-shaped response function with respect to temperature and a U-shaped response to precipitation, but we omit them from both figures because they are at an incompatible scale. Figure $4 \mathrm{~b}$ shows that the numbers of dairy cattle and goats are quite stable over a large range of precipitation, but the number of beef cattle and sheep decrease rapidly with more rainfall.

\section{Small and large farms}

In this second analysis, we explored whether small and large livestock farms make different livestock choices. We defined a farm with less than US\$630 worth of animals as a small farm and a farm with more than US\$630 worth as a large farm. On small farms in Africa the livestock is worth US\$230 on average and on large ones US\$7800 on average. Large farms earn over 95\% of the gross revenue from livestock in Africa. Note that pastoralists would generally be included as large farms. Because large farms own a considerable amount of livestock, they tend to be more commercially oriented. In contrast, farms with few livestock tend to be household farms that rely more heavily on household labor and are less engaged in market activities.

We tested whether small and large farms are alike by creating a dummy variable for large farms. In the species choice equation, we introduced a set of interaction terms which are the product of this large farm dummy and each climate variable. These interaction terms measure whether large farms have a different climate response from that of small farms. The total climate response of a large farm is consequently the sum of the original climate coefficient and this interaction term.

Table 4 presents the multinomial logit regression results of species choice with the climate interaction terms. Looking at the large farm-climate interaction terms, we can see that the choice of some species depends on farm size. Large farms react differently from small farms to summer temperature and precipitation for beef cattle, summer precipitation and winter temperature for dairy cattle and sheep, and summer temperature for goats. Looking at the climate coefficients alone, which reflect the sensitivity of small farms, we can see that the choice of beef cattle is not sensitive to climate, whereas the choice of the remaining species is sensitive to summer temperature and summer and winter precipitation. Dairy cattle are also sensitive to winter temperature. 
The number of each species a farm owns also depends on the farm size, as shown in Table 5. Large farms, in general, are more sensitive to hotter temperature. Some large farm interaction terms are significant such as the annual mean precipitation for beef cattle, sheep, and chickens.

Conditional net income is not dependent on farm size. We consequently rely on Table 2 to predict conditional net income per animal.

\section{Climate simulations}

\section{Uniform scenarios}

This analysis examined the consequences of some uniform climate change scenarios. In the warming scenarios, we increased existing temperatures by a constant amount across Africa. In the precipitation scenarios, we changed rainfall proportionally by the same amount across Africa. Although these climate scenarios are simplistic, they provide a sense of how climate change affects model predictions. The scenarios include a uniform increase in temperature of $+2.5^{\circ} \mathrm{C}$ and $+5.0^{\circ} \mathrm{C}$ and a uniform change in precipitation of $-15 \%$ and $+15 \%$ across all of Africa.

We calculate the probability of choosing a particular species at the current climate and for each uniform climate change scenario using the climate parameters in Table 1. The changes in probabilities for each species are shown in Table $6 \mathrm{a}$. With a $2.5^{\circ} \mathrm{C}$ warming, the probability of choosing beef cattle and chickens is predicted to decrease, while the probabilities of choosing goats and sheep are expected to increase. The change in dairy cattle is positive but insignificant. With a $5.0^{\circ} \mathrm{C}$ warming, these effects increase even further. A $15 \%$ increase/decrease in rainfall causes a decrease/increase in the likelihood of choosing beef cattle, dairy cattle and sheep. Chickens and goats, by contrast, are more likely/less likely to be chosen as precipitation increases/decreases. The effects of the tested temperature changes are larger than the effects of the tested precipitation changes.

We calculated the change in conditional net revenue per animal using the climate coefficients in Table 2. The results, shown in Table 6b, reveal that the conditional net revenues for all the animals are sensitive to warming. The net revenue per animal falls with a warming of $2.5^{\circ} \mathrm{C}$. The net revenues for all five animals fall substantially more with an increase of $5^{\circ} \mathrm{C}$, except for goats which are more heat tolerant. The rainfall effect on net revenues is much smaller. A $15 \%$ increase/decrease in rainfall decreases/increases the net revenue for beef cattle, sheep, and chickens, but increases/decreases the net revenue for dairy cattle and goats. These net revenue changes are statistically insignificant except for beef cattle.

We then calculate the number of animals that farms would have under current climate conditions and uniform change future scenarios using the coefficients from Table 3. Table 6c shows the change in the number of each animal chosen given that a farmer has chosen that species. Warming reduces the number of beef cattle and chickens, but increases the number of goats and sheep. Additional warming accelerates this trend. More rainfall also reduces the number of animals per farm, and less rainfall increases the number, with the exception of goats. The rainfall effects are smaller than the temperature effects. The response of many of the range animals (beef 
cattle, dairy cattle and sheep) to increases in precipitation is worth noting. Although it is true that the productivity of pasture may increase with more rainfall, increased rain causes natural ecosystems to move from grassland to forests. In a natural foraging system such as that of Africa, moving from moderate to large amounts of rainfall is therefore not helpful for most livestock (Sankaran et al. 2005).

Combining the results on the probability of species choice, the number of animals, and the conditional net revenue (Tables $6 a, 6 b$, and $6 c$ ), we calculate the expected net revenue per farm in Table $6 \mathrm{~d}$ for various climate change scenarios. The expected net revenue is the product of the conditional net revenues per animal times the number of animals times their probability of being chosen, summed across all species. The expected net revenue from animals on African farms is currently $\$ 3000$ per farm. Our model predicts a $32 \%$ loss in expected net revenue with a $2.5^{\circ} \mathrm{C}$ warming, and a $69 \%$ loss with a $5^{\circ} \mathrm{C}$ warming. These predictions take into account the change in probability of choosing each species, the drop in net revenue per animal, and the reduction in the number of animals of that species. The expected revenues fall with temperature because of reductions in the conditional net income of all species and because of shifts away from highly profitable beef cattle. Rainfall effects are comparably smaller. A 15\% increase in rainfall leads to a loss of $2 \%$ in expected net revenue per household from livestock and a $15 \%$ decrease in rainfall leads to a gain of $2 \%$.

To see how these effects are distributed, we present in Figure 5 the probability of choosing beef cattle in South Africa under the current climate, with $+2.5^{\circ} \mathrm{C}$, and with $+5^{\circ} \mathrm{C}$ warming. With the current climate, beef cattle are evident in large numbers in the southeastern part of the country. However, with $2.5^{\circ} \mathrm{C}$ warming the area suitable for beef cattle shrinks dramatically. With $5^{\circ} \mathrm{C}$ warming, beef cattle disappear almost entirely from Africa. In Figure 6 we show the impact of warming on sheep for all of Africa. There is a widespread reduction of sheep in South Africa with warming. However, near the Sahel sheep flourish with warming. As temperatures warm, sheep are distributed across a much wider area. A similar result applies to goats.

In the remaining uniform simulations, we examine the results for small and large farms. The probabilities of choosing different species is calculated from the climate coefficients in Table 4. Table 7a reveals that warming causes small livestock farms to shift to goats and sheep and away from dairy cattle and chickens. The conditional net revenue effects per animal are calculated from Table 2. Table $7 \mathrm{~b}$ indicates that the net revenue per animal falls as temperatures rise for beef cattle, goats, and chickens, but increases for dairy cattle, especially sheep. The number of animals per farm are calculated from the climate coefficients in Table 5. Table 7c reveals that farmers choose to have fewer of all animals. Finally, Table 7d calculates the expected income of small farmers from the results in Tables $7 \mathrm{a}, 7 \mathrm{~b}$ and $7 \mathrm{c}$. The expected income of small farmers falls by an average of $13 \%$ with $2.5^{\circ} \mathrm{C}$ warming, but by a negligible amount with $5^{\circ} \mathrm{C}$ warming. A $15 \%$ decrease in precipitation is expected to increase small livestock farm incomes by $6 \%$.

The calculations for Table 8 for large farms are similar to the calculation in Table 7 for small farms except that they also rely on the climate coefficients that apply to large farms. Table $8 \mathrm{a}$ reveals that warming causes large livestock farms to shift to dairy cattle and sheep and away from goats, chickens and especially beef cattle. Table $8 \mathrm{~b}$ indicates that the income per animal falls for all species as temperatures rise. The percentage reduction is largest for goats, sheep and chickens but the absolute amount is larger for beef cattle. Table 8c reveals that with higher 
temperatures farmers choose to have fewer beef cattle, chickens and sheep but more goats and dairy cattle. Finally, in Table 8d, large farmers' expected income falls by an average of $26 \%$ with $2.5^{\circ} \mathrm{C}$ warming and $67 \%$ with a $5^{\circ} \mathrm{C}$ warming. A $15 \%$ decrease in precipitation is expected to increase large livestock farmers' incomes by $2 \%$.

\section{AOGCM scenarios}

We also examined a set of climate change scenarios predicted by AOGCMs. The climate scenarios reflect the A1 SRES scenarios from the following models: CCC (Boer et al. 2000), CCSR (Emori et al. 1999), and PCM (Washington et al. 2000). For each model, we examined country level climate change scenarios in 2020, 2060, and 2100. For each climate scenario, we added the change in temperature predicted by each climate model to the baseline temperature in each district. We also multiplied the percentage change in precipitation predicted by each climate model by the baseline precipitation in each district or province. This gave us a new climate for every district in Africa for each model and each time period.

Table 9 summarizes the climate scenarios of the three models for the years 2020, 2060, and 2100. The models predict a broad set of scenarios consistent with the range of outcomes in the most recent IPCC (Intergovernmental Panel on Climate Change) report (Houghton et al. 2001). In $2100, \mathrm{PCM}$ predicts a $2^{\circ} \mathrm{C}$ temperature increase in Africa, CCSR a $4^{\circ} \mathrm{C}$ increase, and CCC a $6^{\circ} \mathrm{C}$ increase. Rainfall predictions are noisier: PCM predicts a $10 \%$ increase in rainfall in Africa, CCC a $10 \%$ decrease, and CCSR a 30\% decrease. In addition to the mean rainfall in Africa varying substantially across the scenarios, there is also substantial variation in rainfall across countries within each scenario.

Examining the path of climate change over time reveals that temperatures are predicted to increase steadily until 2100 for all three models. Precipitation predictions, however, vary across time: CCC predicts a declining trend, CCSR an initial decrease, and then increase, and decrease again, and PCM an initial increase, and then decrease, and increase again.

We used the parameters from our estimated models to simulate the impacts of climate change on the expected revenue of livestock management under various scenarios. Table 10 examines the results using the models estimated for all farms. Table 10a shows the changes in the probabilities of choosing a particular animal for each climate scenario. All the scenarios predict that farmers would choose fewer beef cattle and chickens, but more goats and sheep. The choice of dairy cattle, however, depends on the scenarios. On average, the probabilities of choosing beef cattle decrease by $1 \%$ in $2020,2 \%$ in 2060 and $3 \%$ in 2100 . The probability of choosing sheep increases over the same period.

We show the changes in the conditional net incomes per animal in Table 10b. The CCC model predicts net income from beef cattle will steadily decrease over the next century. PCM predicts a substantial drop in income from beef cattle until 2060, but the drop stabilizes afterwards. CCSR predicts a substantial drop in income from beef cattle through 2060, but an increase afterward. Net incomes for sheep and chickens also decrease over time, but the decreases are smaller. The responses for dairy cattle and goats are dependent on the scenarios, but generally change little. 
Table 10c calculates the changes in the number of animals of each species for each climate scenario. Across all models, the number of beef cattle is predicted to decrease by an average of five per farm in 2020, 10 in 2060, and 15 in 2100. Chickens also decrease in number. In contrast, numbers of goats and sheep are predicted to increase over time. The number of sheep increases rapidly after 2060 according to CCC and CCSR scenarios.

Combining the results from Tables 10a, 10b and 10c, the expected change in net income is shown in Table 10d for each AOGCM scenario. In all cases, there are losses by the year 2020. The CCC scenario predicts a $13 \%$ loss, the PCM scenario a $37 \%$ loss, and the CCSR scenario a $15 \%$ loss in expected net income per household. African farmers are expected to lose income because they must switch to animals that provide lower returns (thus lowering the net income per animal) and reduce the number of animals for most species. These net results are consistent with a traditional Ricardian analysis of the same data (Seo \& Mendelsohn 2006a). The damage increases over time: by 2060 between 15 and $40 \%$ of expected income is lost, and between 40 and $70 \%$ by 2100 .

The $95 \%$ confidence interval was calculated for all of these estimates using 200 bootstrap runs. The impact estimates are significant for both uniform temperature change scenarios and uniform precipitation change scenarios. They are also significant for the AOGCM scenarios in 2020, 2060, and 2100 .

Table 10d also shows the aggregate impact across Africa. The results suggest that the livestock damage will vary from a loss of $\$ 8$ to $\$ 23$ billion in livestock income in 2020 , from to $\$ 9$ to $\$ 24$ billion in 2060, and from $\$ 25$ to $\$ 40$ billion in 2100 . The PCM scenario predicts little change from 2020 to 2060, and the CCSR scenario predicts the smallest loss in 2100 among the models due to the large decrease in rainfall predicted in this period. The expected income from livestock will fall because of warming but it will rise in some dry scenarios as farmers shift from crops to livestock.

The remaining analysis looks at the consequences of the AOGCM scenarios for small and large livestock farms. Table 11a examines how species choice changes with each AOGCM for small farms. In 2100 , the CCC model predicts that dairy cattle and sheep will be chosen more often as the primary animal and goats and chickens less often. The income per animal will tend to fall over time except for sheep. With the CCC scenario, dairy cattle and sheep will provide a higher income in 2100 . With the CCSR scenario in 2100 , sheep and dairy cattle also provide higher incomes but the effect is much smaller. The number of animals per farm, shown in Table 11c, will tend to fall with warming, again with a few exceptions. With the CCSR and PCM scenarios, the numbers of beef cattle will increase. The changes in the number of goats and sheep are relatively negligible. Finally, in Table 11d, the expected income for small farms will tend to increase over time with the CCC scenario up to $\$ 36$ per farm or $34 \%$ in 2100 . The income fluctuates with the PCM and CCSR scenarios over time, resulting in an $8 \%$ increase with the PCM scenario and a 5\% decrease with the CCSR scenario in 2100.

Table 12a reveals that large farms in 2100 will shift away from beef cattle, goats and chickens in favor of dairy cattle and sheep with the CCC scenario. However, with the CCSR scenario, large farms will move away from beef cattle in favor of dairy cattle and goats. Finally, there will be little shifting of species in the PCM scenario. Table $12 \mathrm{~b}$ shows that there is a large absolute 
reduction in the net revenue per animal for beef cattle and dairy cattle in the CCC scenario but there is an even larger percentage loss for sheep and chickens in this scenario. In the CCSR scenario, the effects are smaller but the net revenues for sheep and dairy cattle increase while the net revenue for chickens falls. Finally, with the PCM scenario, the net revenue effects are even smaller, with revenues for beef cattle, sheep and goats all falling but increasing for dairy cattle. Table 12c reveals that in the CCC scenario the numbers of beef cattle and chickens will fall on large farms but the number of goats will increase. With the CCSR scenario, the number of sheep will increase. With the PCM scenario, the number of chickens will fall. Table $12 \mathrm{~d}$ pulls all these results together to predict that the CCC scenario will lead to a $\$ 6000$ reduction in expected net revenue per large farm (77\%), the CCSR to a $\$ 2700$ reduction (34\%), and the PCM to a $\$ 3400$ reduction $(43 \%)$.

The effect of global warming on large farms is considerably more severe than on small farms in Africa. In order to understand this result, it is helpful to know which species small and large farms depend upon for income. Currently, small farmers get $60 \%$ of their livestock income from dairy cattle, $13 \%$ from goats and 13\% from sheep. Only 5\% of their income comes from beef cattle. In contrast, large livestock farms get $61 \%$ of their income from beef cattle and another $32 \%$ from dairy cattle. Small farms are well diversified, whereas large farms are specialized in cattle, especially beef cattle. Commercial beef cattle prosper in temperate climates but respond poorly to high temperatures. Large farms consequently suffer large losses in climate scenarios that involve high temperatures, such as CCC. Small farmers, in contrast, have their portfolio in more heat tolerant animals and will therefore gain from climate change according to the CCC scenario.

\section{Conclusion}

This paper develops a new technique, the Structural Ricardian Model, to model a farmer's choice as a simultaneous decision process. Farmers choose the profit maximizing level of inputs for each animal (or crop if applied to crop farming), the species that provides the highest net revenue and the number of animals of that species. The Structural Ricardian Model shows how each of these decisions is influenced by climate, not just the way expected net revenue changes. The model reveals the farmers' underlying decision making and gives insights into how they might adapt to climate change.

We applied this analysis to livestock management in Africa. The multinomial choice model revealed that the probability of selecting beef cattle and chickens will diminish sharply with warming. This is completely consistent with the observation that current beef cattle operations are located only in temperate locations across Africa. Further, the model predicts that numbers of goats and sheep will increase with warming. This again is consistent with observations of where goats and sheep are currently located, in relatively hot locations such as Burkina Faso, Niger and Senegal.

The conditional net revenue analysis supports the multinomial choice results. Although the net revenues for all the five major animals will decrease with warming, beef cattle will be the most severely affected. Consequently, farmers will switch from beef cattle as temperatures rise. 
Finally, the results of the model predicting the number of animals of each species is also consistent with the results from the multinomial logit choice and conditional net revenue analysis. All species will be hurt by warming and so there will be fewer animals per farm. Beef cattle is especially vulnerable. The net profitability of livestock will be reduced and so farmers will reduce their investments in livestock and shift away from beef cattle.

There has been very little quantitative research on animal husbandry in Africa so there are few empirical studies to compare these results with. A standard Ricardian analysis was done by Seo \& Mendelsohn (2006a), using the same data. The results of the standard Ricardian model are quite similar to the results in this paper. That is, the model predicts that net revenues will fall with either rising temperature or rising rainfall levels.

All the AOGCM predictions suggest that African livestock will be damaged as early as 2020 . Even small changes in temperature will be sufficient to have a relatively large effect on beef cattle operations. Additional warming is expected to exacerbate these damages. Farmers dependent on beef cattle will be especially hard hit. In contrast, small farms who can switch to sheep or goats may not be as vulnerable to higher temperatures compared to large farms that cannot make this switch. Precipitation also plays an important role in the AOGCM results. Scenarios with less precipitation are less harmful. Because pastures and ecosystems in general are more productive with more rain, this result may seem counterintuitive. However, in Africa, lower precipitation may reduce animal diseases that are quite significant for livestock. Perhaps more importantly, less rain shifts forest ecosystems to savanna or grasslands. These grasslands are more productive for sheep, dairy cattle and beef cattle. Reductions in precipitation from large to moderate levels appear to be beneficial to livestock. As long as there is sufficient precipitation to support grasslands, the livestock will gain.

It is important to note that the economic viability of large livestock operations is more vulnerable to warming, largely because they depend on beef cattle. Although commercial scale livestock operations do well in temperate parts of Africa today, they have few alternatives with warming. Warming will force reductions in beef and dairy cattle, critical to many commercial enterprises. In contrast, small farmers have many substitutes. If it gets warmer, they can shift to heat tolerant animals such as goats and sheep. In these circumstances, small farmers in Africa are actually better able to adapt to climate change than their larger more modern counterparts.

It is interesting to compare the results of this analysis with the Ricardian study of livestock (Seo \& Mendelsohn 2006a). This study predicts that large livestock farms will be hurt by warming but that small farms will in fact gain. These qualitative results are also supported in this paper. The Ricardian study predicts a range of expected income effects from climate change depending on how the model is estimated. The structural results are in the middle of this range. The structural results are different but consistent with the more traditional Ricardian model predictions.

This analysis reveals that farmers will most likely adapt to climate change. It suggests that farmers will switch species and move away from cattle and towards goats and sheep. Small farmers will be able to make these changes without much change in expected income. However, these changes are predicted to reduce the net incomes of large farms considerably. African policy makers must be careful to encourage private adaptation during this period of change. There may be nothing that can be done to sustain the large cattle operations that depend on current climate. 
Providing subsidies or other enticements for such operations to continue once the climate changes would only compound the problem. Instead, governments should encourage farmers to change the composition of animals on their farms as needed. That is, they should inform farmers about how other livestock owners have coped with higher temperatures and share indigenous knowledge. Governments should anticipate that farmers will make changes on their lands and do whatever is needed to facilitate these changes. 


\section{REFERENCES}

Adams R et al., 1990. Global climate change and US agriculture. Nature 345: 219-224.

Adams R et al., 1999. The economic effects of climate change on US agriculture. In Mendelsohn $\mathrm{R} \&$ Neumann, J (eds), The Impact of Climate Change on the United States Economy, Cambridge, UK: Cambridge University Press.

Boer G, Flato G \& Ramsden D, 2000. A transient climate change simulation with greenhouse gas and aerosol forcing: Projected climate for the 21 st century. Climate Dynamics 16: $427-$ 450 .

Bourguignon F, Fournier M \& Gurgand M, 2004. Selection bias corrections based on the multinomial logit model: Monte-Carlo comparisons. DELTA Working Paper No. 20, École Normale Supérieure.

Chib S \& Greenberg E, 1998. An analysis of multivariate probit models. Biometrika 85: 347 361.

Chow G, 1983. Econometrics. New York: McGraw-Hill.

Dinar A, Hassan R, Kurukulasuriya P, Benhin J \& Mendelsohn R, 2006. The policy nexus between agriculture and climate change in Africa. A synthesis of the investigation under the GEF / WB Project, Regional Climate, Water and Agriculture: Impacts on and Adaptation of Agro-ecological Systems in Africa. CEEPA Discussion Paper No. 39, Centre for Environmental Economics and Policy in Africa, University of Pretoria.

Dubin JA \& McFadden DL, 1984. An econometric analysis of residential electric appliance holdings and consumption. Econometrica 52(2): 345-362.

Emori, S, Nozawa T, Abe-Ouchi A, Namaguti A \& Kimoto M, 1999. Coupled ocean-atmospheric model experiments of future climate change with an explicit representation of sulfate aerosol scattering. Journal of the Meteorological Society of Japan 77: 1299-1307.

Ford J \& Katondo K, 1977. The distribution of tsetse flies in Africa. Organization of African Unity, Nairobi, Kenya.

Greene WH, 1998. Econometric Analysis (3rd edition). New Jersey: Prentice Hall.

Heckman JJ, 1979. Sample selection bias as a specification error. Econometrica 47(1): 153-162.

Houghton JT et al. (eds), 2001. Climate Change 2001: The Scientific Basis. Contribution of Working Group I to the third assessment report of the Intergovernmental Panel on Climate Change. Cambridge: Cambridge University Press.

Kurukulasuriya P \& Mendelsohn R, 2006. A Ricardian analysis of the impact of climate change on African cropland. CEEPA Discussion Paper No. 8, Centre for Environmental 
Economics and Policy in Africa, University of Pretoria.

McFadden DL, 1981. Econometric models of probabilistic choice. In McFadden, DL, Structural Analysis of Discrete Data and Econometric Applications. Cambridge: MIT press.

McFadden DL, 1999. Chapter 1. Discrete Response Models. University of California at Berkeley, Lecture Notes.

Mendelsohn R (ed), 2001. Global Warming and the American Economy: A Regional Analysis. Edward Elgar, Northhampton, MA, USA.

Mendelsohn R, Nordhaus WD \& Shaw D, 1994. The impact of global warming on agriculture: A Ricardian analysis. American Economic Review 84: 753-771.

Pearce D et al., 1996. The social costs of climate change: Greenhouse damage and benefits of control. In Bruce J, Lee H \& Haites E (eds), Climate Change 1995: Economic and Social Dimensions of Climate Change. Cambridge: Cambridge University Press, pp.179-224.

Reilly J et al., 1996. Agriculture in a changing climate: Impacts and adaptations. In Watson R, Zinyowera M, Moss R \& Dokken D (eds), 1996. Climate Change 1995: Impacts, Adaptations, and Mitigation of Climate Change: Scientific-Technical Analyses, Cambridge: Cambridge University Press for the Intergovernmental Panel on Climate Change (IPCC).

Sankaran M ET AL., 2005. Determinants of woody cover in African savannas, Nature 438: 846849.

Seo SN \& Mendelsohn R, 2006a. Climate change impacts on animal husbandry in Africa: A Ricardian analysis. CEEPA Discussion Paper No. 9, Centre for Environmental Economics and Policy in Africa, University of Pretoria.

Seo S N \& Mendelsohn R, 2006b. Climate change adaptation in Africa: A microeconomic analysis of livestock choice. CEEPA Discussion Paper No. 19, Centre for Environmental Economics and Policy in Africa, University of Pretoria.

Seo SN, Mendelsohn R \& Munasinghe M, 2005. Climate change impacts on agriculture in Sri Lanka. Environment and Development Economics 10: 581-596.

Train K, 2003. Discrete Choice Methods with Simulation. Cambridge, UK: Cambridge University Press.

Washington W et al., 2000. Parallel Climate Model (PCM): Control and transient scenarios. Climate Dynamics 16: 755-774. 
Table 1: Multinomial logit selection model

\begin{tabular}{|c|c|c|c|c|c|c|}
\hline \multirow[b]{2}{*}{ Variable } & \multicolumn{3}{|c|}{ Beef cattle } & \multicolumn{3}{|c|}{ Dairy cattle } \\
\hline & Estimate & $\chi^{2}$ & Odds ratio & Estimate & $\chi^{2}$ & Odds ratio \\
\hline Intercept & -2.916 & 1.450 & & 13.336 & 74.287 & \\
\hline Temperature summer & 0.496 & 6.711 & 1.642 & -1.145 & 100.922 & 0.318 \\
\hline Temperature summer sq & -0.014 & 11.261 & 0.986 & 0.019 & 58.532 & 1.019 \\
\hline Precipitation summer & 0.015 & 14.592 & 1.015 & -0.022 & 49.731 & 0.978 \\
\hline Precipitation summer sq & 0.000 & 28.270 & 1.000 & 0.000 & 15.070 & 1.000 \\
\hline Temperature winter & -0.556 & 19.712 & 0.573 & 0.175 & 2.290 & 1.192 \\
\hline Temperature winter sq & 0.018 & 23.700 & 1.018 & 0.004 & 1.571 & 1.004 \\
\hline Precipitation winter & -0.004 & 0.501 & 0.996 & -0.032 & 43.425 & 0.969 \\
\hline Precipitation winter sq & 0.000 & 0.439 & 1.000 & 0.000 & 9.098 & 1.000 \\
\hline West Africa & -1.088 & 22.092 & 0.337 & -3.092 & 226.729 & 0.045 \\
\hline Large farms & 4.097 & 540.972 & 60.178 & 2.654 & 416.886 & 14.209 \\
\hline Electricity & 0.785 & 17.854 & 2.192 & 0.599 & 13.550 & 1.821 \\
\hline
\end{tabular}

Table 1: (continued)

Goats Sheep

\begin{tabular}{lcccccc} 
Variable & Estimate & $\chi^{2}$ & Odds ratio & Estimate & $\chi^{2}$ & Odds ratio \\
\hline Intercept & 6.564 & 14.871 & & 12.307 & 51.906 & \\
Temperature summer & -0.804 & 50.026 & 0.448 & -0.803 & 43.024 & 0.448 \\
Temperature summer sq & 0.016 & 48.575 & 1.016 & 0.014 & 33.097 & 1.014 \\
Precipitation summer & -0.007 & 6.668 & 0.993 & -0.007 & 4.020 & 0.993 \\
Precipitation summer sq & 0.000 & 9.204 & 1.000 & 0.000 & 0.185 & 1.000 \\
Temperature winter & 0.174 & 1.511 & 1.191 & -0.404 & 12.038 & 0.668 \\
Temperature winter sq & -0.001 & 0.019 & 0.999 & 0.015 & 22.158 & 1.015 \\
Precipitation winter & -0.024 & 24.591 & 0.977 & -0.027 & 23.462 & 0.974 \\
Precipitation winter sq & 0.000 & 16.397 & 1.000 & 0.000 & 6.173 & 1.000 \\
West Africa & 0.446 & 6.735 & 1.562 & 0.935 & 20.778 & 2.547 \\
Large farms & 0.888 & 51.060 & 2.429 & 1.694 & 182.293 & 5.440 \\
Electricity & -0.048 & 0.112 & 0.953 & 0.320 & 4.606 & 1.378 \\
\hline
\end{tabular}

Note: Likelihood ratio test: $\mathrm{P}<0.0001$, Lagrange multiplier test: $\mathrm{P}<0.0001$, Wald test: $\mathrm{P}<0.0001$ 
Table 2: Conditional net revenue per animal regression

Beef cattle

Dairy cattle

Chickens

\begin{tabular}{lcccccc} 
Variable & Estimate & T-statistic & Estimate & T-statistic & Estimate & T-statistic \\
\hline Intercept & 846.23 & 2.55 & -479.90 & -1.57 & 6.92 & 2.73 \\
Temperature mean & -12.12 & -0.37 & 66.37 & 2.24 & -0.41 & -1.73 \\
Temperature mean sq & -0.08 & -0.10 & -1.67 & -2.3 & 0.01 & 1.03 \\
Precipitation mean & -6.64 & -6.30 & -3.40 & -5.03 & -0.02 & -4.16 \\
Precipitation mean sq & 0.03 & 3.93 & 0.02 & 4.48 & 0.00 & 3.74 \\
West Africa & 11.01 & 0.22 & -7.75 & -0.54 & 0.00 & 0.01 \\
Livestock products & -36.86 & -2.74 & 43.45 & 3.84 & 1.20 & 8.83 \\
Cattle beef - selection & & & -113.57 & -3.62 & -1.40 & -2.97 \\
Cattle dairy - selection & 77.43 & 1.39 & & & 1.45 & 2.4 \\
Goats - selection & -134.78 & -0.89 & 72.22 & 0.66 & -1.70 & -2.37 \\
Sheep - selection & 222.06 & 1.05 & 135.43 & 1.36 & 1.25 & 1.29 \\
Chickens - selection & -129.12 & -1.84 & -116.15 & -2.69 & & \\
ADJ RSQ & 0.54 & & 0.15 & & 0.20 & \\
N & 548 & & 1084 & & 1047 & \\
& & & & & &
\end{tabular}

Table 2: (continued)

\begin{tabular}{|c|c|c|c|c|}
\hline \multirow[b]{2}{*}{ Variable } & \multicolumn{2}{|c|}{ Goats } & \multicolumn{2}{|c|}{ Sheep } \\
\hline & Estimate & T-statistic & Estimate & T-statistic \\
\hline Intercept & 70.29 & 4.45 & 119.95 & 6.51 \\
\hline Temperature mean & -4.69 & -3.69 & -6.90 & -4.13 \\
\hline Temperature mean sq & 0.09 & 3.24 & 0.12 & 3.27 \\
\hline Precipitation mean & -0.17 & -4.01 & -0.49 & -8.48 \\
\hline Precipitation mean sq & 0.00 & 6.05 & 0.00 & 7.88 \\
\hline West Africa & 7.49 & 2.46 & 5.16 & 0.92 \\
\hline Livestock products & 10.54 & 12.88 & 8.71 & 7.55 \\
\hline Cattle beef - selection & -7.38 & -2.32 & -0.88 & -0.32 \\
\hline Cattle dairy - selection & 2.34 & 0.67 & 9.17 & 2.23 \\
\hline Goats - selection & & & -17.61 & -2.93 \\
\hline Sheep - selection & 7.43 & 1.35 & & \\
\hline Chickens - selection & -0.14 & -0.06 & 10.73 & 2.31 \\
\hline ADJ RSQ & 0.28 & & 0.22 & \\
\hline $\mathrm{N}$ & 1096 & & 908 & \\
\hline
\end{tabular}


Table 3: Conditional number of animals regression

Beef cattle

Dairy cattle

Chickens

\begin{tabular}{lcccccc} 
Variable & Estimate & T-statistic & Estimate & T-statistic & Estimate & T-statistic \\
\hline Intercept & -21.27 & -0.09 & -49.65 & -1.30 & -3283.10 & -1.57 \\
Annual temperature & 24.49 & 1.12 & 4.11 & 1.10 & 604.30 & 3.13 \\
Temperature sq & -0.73 & -1.31 & -0.08 & -0.86 & -18.65 & -4.09 \\
Annual precipitation & -1.50 & -1.89 & -0.03 & -0.31 & -34.89 & -5.36 \\
Precipitation sq & 0.00 & 0.69 & 0.00 & 0.11 & 0.10 & 2.88 \\
Electricity dummy & 66.98 & 5.79 & 7.61 & 3.57 & 86.82 & 0.49 \\
\% pasture & 9.30 & 0.18 & & & -1061.09 & -2.02 \\
Livestock products & & & 36.71 & 4.40 & & \\
Cattle beef-selection & & & -6.97 & -1.55 & -4075.22 & -9.02 \\
Cattle dairy - selection & 54.40 & 2.47 & & & 1742.12 & 4.74 \\
Goats - selection & -155.51 & -1.53 & 29.85 & 2.16 & -3724.64 & -4.48 \\
Sheep - selection & 74.73 & 0.91 & -21.25 & -1.62 & 4735.25 & 6.00 \\
Chickens - selection & 44.75 & 1.05 & -1.46 & -0.27 & & \\
ADJ RSQ & 0.43 & & 0.21 & & 0.09 & \\
N & 508 & & 1084 & & 1047 & \\
& & & & & & \\
\hline
\end{tabular}

Table 3: (continued)

Goats Sheep

\begin{tabular}{lcccc} 
Variable & Estimate & T-statistic & Estimate & T-statistic \\
\hline Intercept & -68.63 & -4.25 & 131.95 & 1.94 \\
Annual temperature & 3.64 & 3.02 & -10.24 & -1.81 \\
Temperature sq & -0.06 & -2.49 & 0.21 & 1.75 \\
Annual precipitation & 0.03 & 0.75 & -1.32 & -6.23 \\
Precipitation sq & 0.00 & 2.05 & 0.01 & 5.15 \\
\% pasture & -3.45 & -2.95 & 203.23 & 11.64 \\
Electricity dummy & 2.28 & 2.57 & 2.02 & 0.38 \\
Livestock products & & & -2.34 & -0.59 \\
Cattle beef - selection & 5.25 & 1.52 & -126.91 & -11.06 \\
Cattle dairy - selection & -2.95 & -1.27 & 70.85 & 6.60 \\
Goats - selection & & & 21.63 & 1.03 \\
Sheep - selection & -24.52 & -6.19 & & \\
Chickens - selection & 8.99 & 4.04 & 17.42 & 1.04 \\
ADJ RSQ & 0.56 & & 0.38 & \\
N & 1096 & & 908 & \\
& & & & \\
\hline
\end{tabular}


Table 4: Multinomial logit species choice with large farm interactions

\begin{tabular}{|c|c|c|c|c|c|c|}
\hline \multirow[b]{2}{*}{ Variable } & \multicolumn{3}{|c|}{ Beef cattle } & \multicolumn{3}{|c|}{ Dairy cattle } \\
\hline & Estimate & $\chi^{2}$ & Odds ratio & Estimate & $\chi^{2}$ & Odds ratio \\
\hline Intercept & 3.996 & 0.939 & & 26.743 & 153.151 & \\
\hline Temperature summer & -0.262 & 0.671 & 0.770 & -1.673 & 109.630 & 0.188 \\
\hline Temperature summer sq & 0.004 & 0.299 & 1.004 & 0.026 & 58.193 & 1.027 \\
\hline Precipitation summer & -0.002 & 0.043 & 0.998 & -0.044 & 93.672 & 0.957 \\
\hline Precipitation summer sq & 0.000 & 0.250 & 1.000 & 0.000 & 51.533 & 1.000 \\
\hline Temperature winter & -0.375 & 1.856 & 0.688 & -0.428 & 7.394 & 0.652 \\
\hline Temperature winter sq & 0.014 & 2.880 & 1.014 & 0.022 & 22.795 & 1.022 \\
\hline Precipitation winter & -0.004 & 0.129 & 0.996 & -0.032 & 26.882 & 0.968 \\
\hline Precipitation winter sq & 0.000 & 0.069 & 1.000 & 0.000 & 4.051 & 1.000 \\
\hline $\begin{array}{l}\text { Temperature summer* B } \\
\text { Temp summer sq* B }\end{array}$ & $\begin{array}{c}0.947 \\
-0.019\end{array}$ & $\begin{array}{l}4.032 \\
3.565\end{array}$ & $\begin{array}{l}2.578 \\
0.981\end{array}$ & $\begin{array}{c}0.585 \\
-0.004\end{array}$ & $\begin{array}{l}2.786 \\
0.286\end{array}$ & $\begin{array}{l}1.795 \\
0.996\end{array}$ \\
\hline Precipitation summer $* \mathrm{~B}$ & 0.038 & 13.869 & 1.038 & 0.047 & 37.306 & 1.048 \\
\hline Prec summer sq* B & 0.000 & 9.337 & 1.000 & 0.000 & 32.427 & 1.000 \\
\hline Temperature winter $* \mathrm{~B}$ & -0.269 & 0.642 & 0.764 & 0.750 & 8.575 & 2.117 \\
\hline Temp winter sq $* \mathrm{~B}$ & 0.007 & 0.432 & 1.007 & -0.022 & 8.545 & 0.978 \\
\hline Precipitation winter* B & -0.007 & 0.156 & 0.993 & -0.004 & 0.078 & 0.996 \\
\hline Prec winter sq ${ }^{*} \mathrm{~B}$ & 0.000 & 0.852 & 1.000 & 0.000 & 1.379 & 1.000 \\
\hline West Africa & -1.647 & 41.268 & 0.193 & -3.767 & 248.382 & 0.023 \\
\hline Large farms & -6.469 & 1.115 & 0.002 & -16.155 & 11.626 & 0.000 \\
\hline Electricity & 0.912 & 21.854 & 2.490 & 0.741 & 17.890 & 2.097 \\
\hline
\end{tabular}

Note: B is large farm dummy. 
Table 4: (continued)

\begin{tabular}{|c|c|c|c|c|c|c|}
\hline \multirow[b]{2}{*}{ Variable } & \multicolumn{3}{|c|}{ Goats } & \multicolumn{3}{|c|}{ Sheep } \\
\hline & Estimate & $\chi^{2}$ & Odds ratio & Estimate & $\chi^{2}$ & Odds ratio \\
\hline Intercept & 2.284 & 1.269 & 9.813 & 6.876 & 8.708 & \\
\hline Temperature summer & -0.622 & 22.297 & 0.537 & -0.788 & 28.011 & 0.455 \\
\hline Temperature summer sq & 0.013 & 25.081 & 1.014 & 0.014 & 21.281 & 1.014 \\
\hline Precipitation summer & -0.004 & 1.710 & 0.996 & -0.013 & 12.773 & 0.987 \\
\hline Precipitation summer sq & 0.000 & 5.730 & 1.000 & 0.000 & 3.931 & 1.000 \\
\hline Temperature winter & 0.338 & 3.236 & 1.403 & 0.122 & 0.358 & 1.129 \\
\hline Temperature winter sq & -0.006 & 1.289 & 0.994 & 0.004 & 0.434 & 1.004 \\
\hline Precipitation winter & -0.019 & 13.052 & 0.982 & -0.019 & 9.311 & 0.981 \\
\hline Precipitation winter sq & 0.000 & 8.604 & 1.000 & 0.000 & 0.576 & 1.000 \\
\hline Temperature summer $* \mathrm{~B}$ & -0.838 & 5.553 & 0.433 & -0.387 & 1.136 & 0.679 \\
\hline Temp summer sq *B & 0.016 & 4.569 & 1.016 & 0.011 & 2.109 & 1.011 \\
\hline Precipitation summer $* B$ & -0.004 & 0.238 & 0.996 & 0.029 & 13.436 & 1.029 \\
\hline Prec summer sq $* B$ & 0.000 & 0.171 & 1.000 & 0.000 & 15.884 & 1.000 \\
\hline Temperature winter $* \mathrm{~B}$ & -0.211 & 0.442 & 0.810 & -0.760 & 6.891 & 0.468 \\
\hline Temp winter sq $* \mathrm{~B}$ & 0.008 & 0.931 & 1.009 & 0.017 & 4.363 & 1.017 \\
\hline Precipitation winter $* \mathrm{~B}$ & -0.023 & 2.634 & 0.977 & -0.020 & 1.990 & 0.980 \\
\hline Prec winter sq ${ }^{*} \mathrm{~B}$ & 0.000 & 2.601 & 1.000 & 0.000 & 4.199 & 1.000 \\
\hline West Africa & 0.421 & 5.727 & 1.523 & 0.601 & 8.144 & 1.824 \\
\hline Large farms & 13.186 & 7.040 & 532881 & 11.440 & 5.313 & 92997 \\
\hline Electricity & 0.034 & 0.054 & 1.034 & 0.457 & 9.076 & 1.579 \\
\hline
\end{tabular}

Note: B is large farm dummy. 
Table 5: Conditional number of animals regression with large farm dummy

\begin{tabular}{lcccccc}
\hline & \multicolumn{2}{c}{ Beef cattle } & Dairy cattle & \multicolumn{2}{c}{ Chickens } \\
& & & & & & \\
& & & & & & \\
Variable & Estimate & T-statistic & Estimate & T-statistic & Estimate & T-statistic \\
\hline & 25.46 & 0.10 & -59.01 & -1.53 & -109.48 & -0.07 \\
Intercept & 0.64 & 1.03 & -0.25 & -1.19 & 13.12 & 0.10 \\
Annual temperature & -0.02 & -1.02 & 0.01 & 1.18 & -0.51 & -0.17 \\
Temperature sq & -0.04 & -1.39 & -0.01 & -2.39 & 2.79 & 0.78 \\
Annual precipitation & 0.00 & 1.45 & 0.00 & 1.48 & -0.02 & -0.84 \\
Precipitation sq & 18.66 & 1.02 & 6.91 & 1.31 & 395.30 & 2.70 \\
Annual temp *B & -0.39 & -0.85 & -0.15 & -1.14 & -12.92 & -4.40 \\
Temperature sq *B & -1.71 & -1.91 & -0.13 & -0.94 & -79.69 & -11.80 \\
Annual prec *B & 0.01 & 1.74 & 0.00 & 0.06 & 0.35 & 10.42 \\
Precipitation sq *B & 68.03 & 5.81 & 8.04 & 3.78 & 63.25 & 42.89 \\
Electricity dummy & 78.96 & 1.88 & & & -279.58 & -1.08 \\
\% pasture & & & 40.75 & 5.26 & & \\
Livestock products & & & 11.38 & 0.61 & -437.39 & -0.75 \\
Cattle beef - selection & 17.95 & 0.19 & & & 146.64 & 0.61 \\
Cattle dairy - selection & -147.97 & -0.99 & -2.51 & -0.15 & 50.29 & 0.15 \\
Goats - selection & 28.11 & 0.36 & -22.20 & -1.59 & 141.02 & 0.41 \\
Sheep - selection & 107.65 & 1.05 & 13.36 & 0.94 & & \\
Chickens - selection & 0.22 & & 0.10 & & 0.85 & \\
ADJ RSQ & 508 & & 1084 & & 1047 & \\
N & & & & & & \\
& & & & & & \\
\hline
\end{tabular}

Note: B is large farm dummy. 
Table 5: (continued)

\begin{tabular}{lcccc}
\hline \multicolumn{2}{c}{ Goats } & \multicolumn{2}{c}{ Sheep } \\
& & & & \\
& & & & \\
Variable & Estimate & T-statistic & Estimate & T-statistic \\
\hline & & & & \\
Intercept & 70.34 & 4.29 & 1.96 & 0.03 \\
Annual temperature & -5.36 & -4.13 & 0.10 & 0.12 \\
Temperature sq & 0.10 & 3.53 & -0.01 & -0.41 \\
Annual precipitation & -0.01 & -0.09 & 0.03 & 1.29 \\
Precipitation sq & 0.00 & 0.04 & 0.00 & -0.25 \\
Annual temp *B & 2.38 & 1.55 & -8.43 & -0.71 \\
Temperature sq *B & -0.05 & -1.54 & 0.10 & 0.42 \\
Annual prec *B & -0.23 & -0.69 & -2.31 & -5.13 \\
Precipitation sq *B & 0.00 & 0.61 & 0.01 & 3.93 \\
\% pasture & 0.62 & 0.49 & 245.12 & 14.34 \\
Electricity dummy & 7.06 & 1.80 & 33.58 & 5.11 \\
Livestock products & & & -4.55 & -1.16 \\
Cattle beef - selection & 10.13 & 0.58 & 254.11 & 2.22 \\
Cattle dairy - selection & 3.02 & 0.52 & -68.75 & -1.69 \\
Goats - selection & & & -148.55 & -4.27 \\
Sheep - selection & -4.70 & -1.00 & & \\
Chickens - selection & -6.18 & -0.62 & -59.90 & -1.01 \\
ADJ RSQ & 0.29 & & 0.39 & \\
N & 1096 & & 908 & \\
& & & & \\
\hline
\end{tabular}

Note: B is large farm dummy. 
Table 6a: Predicted change in the probability of selecting each animal from uniform climate scenarios

\begin{tabular}{lccccc}
\hline & Beef cattle & Dairy cattle & Goats & Sheep & Chickens \\
\hline Baseline probability & $11.8 \%$ & $23.1 \%$ & $23.4 \%$ & $19.4 \%$ & $22.3 \%$ \\
Increase temp $2.5^{\circ} \mathrm{C}$ & $-1.7 \%$ & $0.4 \%$ & $0.8 \%$ & $3.3 \%$ & $-2.8 \%$ \\
Increase temp $5{ }^{\circ} \mathrm{C}$ & $-3.8 \%$ & $2.1 \%$ & $0.0 \%$ & $8.7 \%$ & $-7.0 \%$ \\
Decrease rain $15 \%$ & $-0.3 \%$ & $1.8 \%$ & $-1.2 \%$ & $1.1 \%$ & $-1.4 \%$ \\
Increase rain $15 \%$ & $-0.1 \%$ & $-1.5 \%$ & $1.5 \%$ & $-1.1 \%$ & $1.0 \%$ \\
\hline
\end{tabular}

Table 6b: Predicted change in net income per animal from uniform climate scenarios (US\$/animal)

\begin{tabular}{lccccc}
\hline & Beef cattle & Dairy cattle & Goats & Sheep & Chickens \\
\hline Baseline income & 145.54 & 132.09 & 6.49 & 11.77 & 1.14 \\
Increase temp $2.5^{\circ} \mathrm{C}$ & -27.80 & -3.40 & -0.81 & -2.55 & -0.34 \\
Increase temp $5^{\circ} \mathrm{C}$ & -47.09 & -21.36 & -0.54 & -3.49 & -0.55 \\
Decrease rain $15 \%$ & 13.91 & -0.42 & -0.06 & 1.03 & 0.03 \\
Increase rain $15 \%$ & -7.08 & 3.78 & 0.29 & -0.58 & -0.02 \\
\hline
\end{tabular}

Table 6c: Predicted change in number of each animal per farm from uniform climate scenarios (animals/household)

\begin{tabular}{lccccc}
\hline & Beef cattle & Dairy cattle & Goats & Sheep & Chickens \\
\hline Baseline number & 63.47 & 23.84 & 15.36 & 34.05 & 790.09 \\
Increase temp $25^{\circ} \mathrm{C}$ & -9.00 & 1.84 & 1.45 & 0.35 & -112.61 \\
Increase temp $5^{\circ} \mathrm{C}$ & -18.96 & 2.88 & 2.14 & 3.20 & -183.84 \\
Decrease rain $15 \%$ & 7.52 & 0.13 & -0.90 & 2.99 & 50.30 \\
Increase rain $15 \%$ & -6.33 & -0.11 & 0.99 & -1.80 & -45.20 \\
& & & & & \\
\hline
\end{tabular}

Table 6d: Predicted change in expected income from uniform climate scenarios (US\$)

\begin{tabular}{ccccc}
$\begin{array}{c}\text { Mean } \\
\text { (US\$/farm) }\end{array}$ & $\begin{array}{c}\text { Total } \\
\text { (billions US\$) }\end{array}$ & \% change & $\begin{array}{c}\text { Bootstrap } \\
\text { lower 95 \% }\end{array}$ & $\begin{array}{c}\text { Bootstrap } \\
\text { upper 95\% }\end{array}$ \\
\hline 3023 & 60 & & & \\
-964 & -19 & $-31.90 \%$ & -1077 & -722 \\
-2083 & -41 & $-68.89 \%$ & -2452 & -1631 \\
184 & 2 & $2.49 \%$ & 139 & 207 \\
-108 & -2 & $-1.88 \%$ & -111 & -60 \\
\hline
\end{tabular}


Table 7a: Predicted change in the probability of selecting each animal from uniform climate scenarios for small farms

\begin{tabular}{lccccc}
\hline & Beef cattle & Dairy cattle & Goats & Sheep & Chickens \\
& & & & & \\
\hline Baseline probability & $2.20 \%$ & $15.40 \%$ & $29.60 \%$ & $18.27 \%$ & $34.53 \%$ \\
Increase temp $2.5^{\circ} \mathrm{C}$ & $0.17 \%$ & $-3.27 \%$ & $2.13 \%$ & $4.03 \%$ & $-3.07 \%$ \\
Increase temp $5{ }^{\circ} \mathrm{C}$ & $0.36 \%$ & $0.09 \%$ & $1.27 \%$ & $7.57 \%$ & $-9.29 \%$ \\
Decrease rain $15 \%$ & $0.02 \%$ & $1.69 \%$ & $-1.69 \%$ & $1.48 \%$ & $-1.50 \%$ \\
Increase rain $15 \%$ & $-0.07 \%$ & $-0.95 \%$ & $1.79 \%$ & $-1.39 \%$ & $0.62 \%$ \\
& & & & & \\
\hline
\end{tabular}

Table 7b: Predicted change in net income per animal from uniform climate scenarios for small farms (US\$)

\begin{tabular}{lccccc}
\hline & Beef cattle & Dairy cattle & Goats & Sheep & Chickens \\
\hline Baseline income & 151.38 & 140.98 & 6.55 & 12.89 & 0.86 \\
Increase temp $2.5^{\circ} \mathrm{C}$ & -51.12 & 1.34 & -1.63 & 0.18 & -0.18 \\
Increase temp $5^{\circ} \mathrm{C}$ & -80.99 & 7.90 & -2.24 & 3.78 & -0.18 \\
Decrease rain $15 \%$ & 18.70 & 3.37 & -0.43 & 0.48 & 0.03 \\
Increase rain $15 \%$ & -13.60 & -3.14 & 0.66 & -0.30 & -0.01 \\
& & & & & \\
\hline
\end{tabular}

Table 7c: Predicted change in number of each animal per farm from uniform climate scenarios for small farms (animals/household)

\begin{tabular}{lccccc}
\hline & Beef cattle & Dairy cattle & Goats & Sheep & Chickens \\
\hline Baseline number & 1.48 & 2.92 & 7.09 & 5.83 & 31.10 \\
Increase temp $2.5^{\circ} \mathrm{C}$ & -0.16 & -0.02 & -0.66 & -0.77 & -8.15 \\
Increase temp $5^{\circ} \mathrm{C}$ & -0.05 & -0.00 & -1.17 & -1.64 & -12.13 \\
Decrease rain $15 \%$ & -0.03 & 0.03 & -0.06 & -0.21 & 1.35 \\
Increase rain $15 \%$ & 0.08 & -0.02 & 0.06 & 0.20 & -1.01 \\
& & & & & \\
\hline
\end{tabular}

Table 7d. Predicted change in expected income from uniform climate scenarios for small farms (US\$)

\begin{tabular}{ccccc}
$\begin{array}{c}\text { Mean } \\
\text { (US\$/farm) }\end{array}$ & $\begin{array}{c}\text { Total } \\
\text { (billions US\$) }\end{array}$ & \% change & $\begin{array}{c}\text { Bootstrap } \\
\text { lower 95 \% }\end{array}$ & $\begin{array}{c}\text { Bootstrap } \\
\text { upper 95\% }\end{array}$ \\
\hline 102 & 6.0 & & & \\
-13 & -0.8 & $-12.7 \%$ & -24 & 3 \\
-1 & -0.1 & $-0.9 \%$ & -8 & 6 \\
6 & 0.4 & $5.9 \%$ & 1 & 13 \\
-3 & -0.2 & $-2.9 \%$ & -6 & 4 \\
\hline
\end{tabular}


Table 8a: Predicted change in the probability of selecting each animal from uniform climate scenarios for large farms

\begin{tabular}{lccccc}
\hline & Beef cattle & Dairy cattle & Goats & Sheep & Chickens \\
& & & & & \\
\hline Baseline probability & $24.5 \%$ & $33.4 \%$ & $15.1 \%$ & $20.8 \%$ & $6.1 \%$ \\
Increase temp $2.5^{\circ} \mathrm{C}$ & $-4.6 \%$ & $4.5 \%$ & $-1.5 \%$ & $3.4 \%$ & $-1.8 \%$ \\
Increase temp $5{ }^{\circ} \mathrm{C}$ & $-10.0 \%$ & $8.7 \%$ & $-3.8 \%$ & $8.7 \%$ & $-3.5 \%$ \\
Decrease rain $15 \%$ & $-1.2 \%$ & $1.2 \%$ & $0.1 \%$ & $0.5 \%$ & $-0.6 \%$ \\
Increase rain $15 \%$ & $0.6 \%$ & $-1.0 \%$ & $0.3 \%$ & $-0.6 \%$ & $0.7 \%$ \\
\hline
\end{tabular}

Table 8b: Predicted change in net income per animal from uniform climate scenarios for large farms (US\$)

\begin{tabular}{lccccc}
\hline & Beef cattle & Dairy cattle & Goats & Sheep & Chickens \\
\hline Baseline income & 146.01 & 120.18 & 6.04 & 12.08 & 1.68 \\
Increase temp $2.5^{\circ} \mathrm{C}$ & -15.30 & -3.75 & -1.54 & -5.19 & -0.43 \\
Increase temp $5^{\circ} \mathrm{C}$ & -28.11 & -21.10 & -2.48 & -8.29 & -0.87 \\
Decrease rain $15 \%$ & 12.19 & -1.31 & 0.39 & 1.41 & -0.14 \\
Increase rain $15 \%$ & -4.60 & 9.01 & -0.25 & -0.59 & 0.21 \\
& & & & & \\
\hline
\end{tabular}

Table 8c: Predicted change in number of each animal per farm from uniform climate scenarios for large farms (animals/household)

\begin{tabular}{lccccc}
\hline & Beef cattle & Dairy cattle & Goats & Sheep & Chickens \\
\hline Baseline number & 77.58 & 35.82 & 23.81 & 49.40 & 1907.25 \\
Increase temp $2.5^{\circ} \mathrm{C}$ & -3.64 & 1.26 & 6.85 & -1.27 & -178.14 \\
Increase temp $5^{\circ} \mathrm{C}$ & -13.91 & 1.31 & 15.96 & -4.91 & -369.30 \\
Decrease rain $15 \%$ & 4.86 & 0.36 & 0.76 & 5.75 & 47.37 \\
Increase rain $15 \%$ & -2.20 & -0.54 & -1.20 & -2.69 & -10.11 \\
& & & & & \\
\hline
\end{tabular}

Table 8d. Predicted change in expected income from uniform climate scenarios for large farms (US\$)

\begin{tabular}{ccccc}
$\begin{array}{c}\text { Mean } \\
\text { (US\$/farm) }\end{array}$ & $\begin{array}{c}\text { Total } \\
\text { (billions US\$) }\end{array}$ & \% change & $\begin{array}{c}\text { Bootstrap } \\
\text { lower 95 \% }\end{array}$ & $\begin{array}{c}\text { Bootstrap } \\
\text { upper 95\% }\end{array}$ \\
\hline 7826 & 60 & & & \\
-2033 & -16 & $-26.0 \%$ & -2504 & -1617 \\
-5206 & -40 & $-66.5 \%$ & -6843 & -4664 \\
160 & 1 & $2.0 \%$ & 121 & 199 \\
-152 & -1 & $-1.9 \%$ & -189 & -77 \\
\hline
\end{tabular}


Table 9: African average AOGCM climate scenarios

\begin{tabular}{ccccc}
\hline & Current & $\mathbf{2 0 2 0}$ & $\mathbf{2 0 6 0}$ & $\mathbf{2 1 0 0}$ \\
\hline Temperature $\left({ }^{\circ} \mathrm{C}\right)$ & & & & \\
CCC & & & & \\
CCSR & 23.29 & 24.94 & 26.85 & 29.96 \\
PCM & 23.29 & 25.27 & 26.17 & 27.39 \\
& 23.29 & 23.95 & 24.94 & \\
Rainfall (mm/month) & & & & \\
CCC & & & & 65.79 \\
CCSR & 79.75 & 76.84 & 71.86 & 62.44 \\
PCM & 79.75 & 73.99 & 76.67 & \\
& 79.75 & 89.58 & 80.72 & \\
\hline
\end{tabular}


Table 10a: Predicted change in the probability of selecting each animal from AOGCM climate scenarios

\begin{tabular}{|c|c|c|c|c|c|}
\hline & Beef cattle & Dairy cattle & Goats & Sheep & Chickens \\
\hline Baseline probability & $11.8 \%$ & $23.1 \%$ & $23.4 \%$ & $19.4 \%$ & $22.3 \%$ \\
\hline \multicolumn{6}{|l|}{2020} \\
\hline $\mathrm{CCC}$ & $-1.59 \%$ & $1.31 \%$ & $1.75 \%$ & $1.90 \%$ & $-3.37 \%$ \\
\hline CCSR & $-0.54 \%$ & $-0.10 \%$ & $1.59 \%$ & $1.86 \%$ & $-2.81 \%$ \\
\hline PCM & $-2.10 \%$ & $-1.37 \%$ & $5.51 \%$ & $1.24 \%$ & $-3.28 \%$ \\
\hline \multicolumn{6}{|l|}{2060} \\
\hline $\mathrm{CCC}$ & $-1.70 \%$ & $-1.46 \%$ & $4.69 \%$ & $2.87 \%$ & $-4.40 \%$ \\
\hline CCSR & $-1.24 \%$ & $4.41 \%$ & $-1.90 \%$ & $2.10 \%$ & $-3.38 \%$ \\
\hline PCM & $-2.09 \%$ & $3.99 \%$ & $-2.65 \%$ & $8.62 \%$ & $-7.87 \%$ \\
\hline \multicolumn{6}{|l|}{2100} \\
\hline $\mathrm{CCC}$ & $-3.93 \%$ & $6.81 \%$ & $-5.73 \%$ & $16.69 \%$ & $-13.84 \%$ \\
\hline CCSR & $-3.29 \%$ & $-0.10 \%$ & $4.60 \%$ & $1.88 \%$ & $-3.10 \%$ \\
\hline PCM & $-2.08 \%$ & $-0.87 \%$ & $4.34 \%$ & $4.01 \%$ & $-5.39 \%$ \\
\hline
\end{tabular}

Table 10b: Predicted change in net income per animal from AOGCM climate scenarios (US\$/animal)

\begin{tabular}{|c|c|c|c|c|c|}
\hline & Beef cattle & Dairy cattle & Goats & Sheep & Chickens \\
\hline Baseline income & 145.00 & 132.09 & 6.49 & 11.77 & 1.14 \\
\hline \multicolumn{6}{|l|}{2020} \\
\hline $\mathrm{CCC}$ & -12.45 & 0.48 & -0.36 & -1.49 & -0.24 \\
\hline CCSR & -22.68 & -2.59 & -0.22 & -0.92 & -0.28 \\
\hline PCM & -14.07 & 12.49 & 0.01 & -1.12 & -0.11 \\
\hline \multicolumn{6}{|l|}{2060} \\
\hline $\mathrm{CCC}$ & -21.46 & 12.66 & -0.21 & -1.72 & -0.22 \\
\hline CCSR & -58.13 & -6.06 & -0.33 & -2.68 & -0.39 \\
\hline PCM & -27.58 & -4.62 & 0.24 & -2.29 & -0.43 \\
\hline \multicolumn{6}{|l|}{2100} \\
\hline $\mathrm{CCC}$ & -42.92 & -22.32 & 1.90 & -1.74 & -0.67 \\
\hline CCSR & -9.32 & 53.50 & 2.13 & 4.29 & -0.32 \\
\hline PCM & -27.61 & 17.21 & 0.25 & -1.30 & -0.31 \\
\hline
\end{tabular}


Table 10c: Predicted change in number of each animal per farm from AOGCM climate scenarios (animals/farm)

\begin{tabular}{|c|c|c|c|c|c|}
\hline \multirow[b]{2}{*}{ Baseline number } & \multirow{2}{*}{$\begin{array}{c}\text { Beef cattle } \\
63\end{array}$} & \multirow{2}{*}{$\begin{array}{c}\text { Dairy cattle } \\
24\end{array}$} & \multirow{2}{*}{$\begin{array}{c}\text { Goats } \\
15\end{array}$} & \multirow{2}{*}{$\begin{array}{c}\text { Sheep } \\
34\end{array}$} & \multirow{2}{*}{$\begin{array}{c}\text { Chickens } \\
790\end{array}$} \\
\hline & & & & & \\
\hline \multicolumn{6}{|l|}{2020} \\
\hline $\mathrm{CCC}$ & -3 & 1 & 1 & 1 & -57 \\
\hline CCSR & -7 & 1 & 0 & 3 & -64 \\
\hline PCM & -8 & 0 & 1 & -2 & -84 \\
\hline \multicolumn{6}{|l|}{2060} \\
\hline $\mathrm{CCC}$ & -9 & 1 & 1 & -2 & -103 \\
\hline CCSR & -11 & 2 & 2 & 0 & -128 \\
\hline PCM & -9 & 2 & 1 & 3 & -115 \\
\hline \multicolumn{6}{|l|}{2100} \\
\hline $\mathrm{CCC}$ & -21 & 3 & 0 & 12 & -171 \\
\hline CCSR & -6 & 3 & 1 & 23 & -6 \\
\hline PCM & -12 & 2 & 2 & 2 & -129 \\
\hline
\end{tabular}

Table 10d. Predicted change in expected income from AOGCM climate scenarios (US\$)

\begin{tabular}{|c|c|c|c|c|c|}
\hline \multirow[b]{2}{*}{ Expected income } & \multirow{2}{*}{$\begin{array}{c}\begin{array}{c}\text { Mean } \\
\text { (US\$/farm) }\end{array} \\
3023\end{array}$} & \multirow{2}{*}{$\begin{array}{c}\text { Total } \\
\text { (billions US\$) } \\
60\end{array}$} & \multirow[t]{2}{*}{$\%$ change } & \multirow[t]{2}{*}{$\begin{array}{c}\text { Bootstrap } \\
\text { lower } 95 \%\end{array}$} & \multirow[t]{2}{*}{$\begin{array}{r}\text { Bootstrap } \\
\text { upper } 95 \%\end{array}$} \\
\hline & & & & & \\
\hline \multicolumn{6}{|l|}{2020} \\
\hline $\mathrm{CCC}$ & -423 & -8 & $-14.0 \%$ & -444 & -278 \\
\hline CCSR & -465 & -9 & $-15.4 \%$ & -487 & -296 \\
\hline $\mathrm{PCM}$ & -1135 & -23 & $-37.5 \%$ & -1710 & -640 \\
\hline \multicolumn{6}{|l|}{2060} \\
\hline $\mathrm{CCC}$ & -1229 & -24 & $-40.6 \%$ & -1768 & -682 \\
\hline CCSR & -445 & -9 & $-14.7 \%$ & -528 & -23 \\
\hline PCM & -1091 & -22 & $-36.1 \%$ & -1348 & -806 \\
\hline \multicolumn{6}{|l|}{2100} \\
\hline $\mathrm{CCC}$ & -2200 & -44 & $-72.8 \%$ & -2783 & -1697 \\
\hline CCSR & -1261 & -25 & $-41.7 \%$ & -1604 & -893 \\
\hline PCM & -1437 & -29 & $-47.5 \%$ & -1989 & -847 \\
\hline
\end{tabular}


Table 11a: Predicted change in the probability of selecting each animal from AOGCM climate scenarios for small farms

\begin{tabular}{|c|c|c|c|c|c|}
\hline & Beef cattle & Dairy cattle & Goats & Sheep & Chickens \\
\hline Baseline probability & $2.20 \%$ & $15.40 \%$ & $29.60 \%$ & $18.27 \%$ & $34.53 \%$ \\
\hline \multicolumn{6}{|l|}{2020} \\
\hline $\mathrm{CCC}$ & $0.2 \%$ & $-1.0 \%$ & $0.7 \%$ & $2.6 \%$ & $-4.1 \%$ \\
\hline CCSR & $0.3 \%$ & $-1.7 \%$ & $0.9 \%$ & $2.8 \%$ & $-3.0 \%$ \\
\hline PCM & $-0.1 \%$ & $2.0 \%$ & $1.5 \%$ & $0.6 \%$ & $-6.0 \%$ \\
\hline \multicolumn{6}{|l|}{2060} \\
\hline $\mathrm{CCC}$ & $0.0 \%$ & $2.4 \%$ & $1.7 \%$ & $1.6 \%$ & $-6.7 \%$ \\
\hline CCSR & $-0.1 \%$ & $4.9 \%$ & $-3.9 \%$ & $3.1 \%$ & $-5.0 \%$ \\
\hline PCM & $0.5 \%$ & $5.7 \%$ & $-4.5 \%$ & $7.8 \%$ & $-9.5 \%$ \\
\hline \multicolumn{6}{|l|}{2100} \\
\hline $\mathrm{CCC}$ & $1.0 \%$ & $20.0 \%$ & $-8.5 \%$ & $1.1 \%$ & $-18.6 \%$ \\
\hline CCSR & $0.0 \%$ & $2.8 \%$ & $-1.3 \%$ & $0.6 \%$ & $-5.7 \%$ \\
\hline PCM & $0.1 \%$ & $4.3 \%$ & $-0.3 \%$ & $1.6 \%$ & $-8.3 \%$ \\
\hline
\end{tabular}

Table 11b: Predicted change in net income per animal from AOGCM climate scenarios for small farms (US\$)

\begin{tabular}{|c|c|c|c|c|c|}
\hline & Beef cattle & Dairy cattle & Goats & Sheep & Chickens \\
\hline Baseline income & 151.38 & 140.98 & 6.55 & 12.89 & 0.86 \\
\hline \multicolumn{6}{|l|}{2020} \\
\hline $\mathrm{CCC}$ & -29.98 & 4.08 & -0.89 & 0.52 & -0.12 \\
\hline CCSR & -37.88 & -1.41 & -1.09 & 1.67 & -0.12 \\
\hline PCM & -29.57 & -14.45 & 0.14 & -0.06 & -0.07 \\
\hline \multicolumn{6}{|l|}{2060} \\
\hline $\mathrm{CCC}$ & -41.28 & -12.05 & -0.88 & -0.54 & -0.12 \\
\hline CCSR & 97.12 & 0.50 & -0.55 & 0.72 & -0.19 \\
\hline PCM & -68.07 & 5.34 & -1.01 & 3.04 & -0.14 \\
\hline \multicolumn{6}{|l|}{2100} \\
\hline $\mathrm{CCC}$ & -94.27 & 21.20 & -1.92 & 10.95 & -0.09 \\
\hline CCSR & -86.76 & 8.88 & -0.90 & 5.91 & -0.06 \\
\hline PCM & -57.88 & -12.26 & -0.94 & 1.16 & -0.15 \\
\hline
\end{tabular}


Table 11c: Predicted change in number of each animal per farm from AOGCM climate scenarios for small farms (animals/farm)

\begin{tabular}{|c|c|c|c|c|c|}
\hline \multirow[b]{2}{*}{ Baseline number } & \multirow{2}{*}{$\begin{array}{c}\text { Beef cattle } \\
1.48\end{array}$} & \multirow{2}{*}{$\begin{array}{c}\text { Dairy cattle } \\
2.92\end{array}$} & \multirow{2}{*}{$\begin{array}{c}\text { Goats } \\
7.09\end{array}$} & \multirow{2}{*}{$\begin{array}{c}\text { Sheep } \\
5.83\end{array}$} & \multirow{2}{*}{$\begin{array}{c}\text { Chickens } \\
31.10\end{array}$} \\
\hline & & & & & \\
\hline \multicolumn{6}{|l|}{2020} \\
\hline $\mathrm{CCC}$ & 0.04 & -0.01 & -0.57 & -0.39 & -3.98 \\
\hline CCSR & 0.05 & -0.02 & -0.70 & -0.57 & -4.28 \\
\hline PCM & 0.21 & -0.01 & 0.01 & 0.34 & -2.81 \\
\hline \multicolumn{6}{|l|}{2060} \\
\hline $\mathrm{CCC}$ & 0.25 & -0.01 & -0.06 & -0.24 & -4.67 \\
\hline CCSR & 0.07 & -0.02 & -0.12 & -0.57 & -6.82 \\
\hline PCM & 0.04 & 0.00 & -1.10 & -0.99 & -5.63 \\
\hline \multicolumn{6}{|l|}{2100} \\
\hline $\mathrm{CCC}$ & -0.09 & 0.19 & -0.27 & -1.96 & -5.26 \\
\hline CCSR & 0.40 & 0.20 & -0.23 & -1.31 & -4.55 \\
\hline PCM & 0.34 & -0.03 & -0.17 & -0.49 & -6.14 \\
\hline
\end{tabular}

Table 11d: Predicted change in expected income from AOGCM climate scenarios for small farms (US\$)

\begin{tabular}{|c|c|c|c|c|c|}
\hline \multirow[b]{2}{*}{ Expected income } & $\begin{array}{c}\text { Mean } \\
\text { (US\$/farm) }\end{array}$ & $\begin{array}{c}\text { Total } \\
\text { (billions US\$) }\end{array}$ & \% change & $\begin{array}{c}\text { Bootstrap } \\
\text { lower } 95 \%\end{array}$ & $\begin{array}{r}\text { Bootstrap } \\
\text { upper } 95 \%\end{array}$ \\
\hline & 106 & 6.00 & & & \\
\hline \multicolumn{6}{|l|}{2020} \\
\hline $\mathrm{CCC}$ & -6 & -0.34 & $-5.7 \%$ & -13 & 1 \\
\hline CCSR & -13 & -0.74 & $-12.3 \%$ & -26 & -1 \\
\hline $\mathrm{PCM}$ & 13 & 0.74 & $12.3 \%$ & 3 & 23 \\
\hline \multicolumn{6}{|l|}{2060} \\
\hline $\mathrm{CCC}$ & 5 & 0.28 & $4.7 \%$ & -5 & 21 \\
\hline CCSR & 16 & 0.91 & $15.1 \%$ & -2 & 23 \\
\hline PCM & -3 & -0.17 & $-2.8 \%$ & -12 & 14 \\
\hline \multicolumn{6}{|l|}{2100} \\
\hline $\mathrm{CCC}$ & 36 & 2.04 & $34.0 \%$ & -5 & 110 \\
\hline CCSR & -6 & -0.34 & $-5.7 \%$ & -24 & 54 \\
\hline PCM & 9 & 0.51 & $8.5 \%$ & -9 & 36 \\
\hline
\end{tabular}


Table 12a: Predicted change in the probability of selecting each animal from AOGCM climate scenarios for large farms

\begin{tabular}{|c|c|c|c|c|c|}
\hline & Beef cattle & Dairy cattle & Goats & Sheep & Chickens \\
\hline Baseline probability & $24.5 \%$ & $33.4 \%$ & $15.1 \%$ & $20.8 \%$ & $6.1 \%$ \\
\hline \multicolumn{6}{|l|}{2020} \\
\hline $\mathrm{CCC}$ & $-3.9 \%$ & $3.2 \%$ & $-0.7 \%$ & $2.6 \%$ & $-1.2 \%$ \\
\hline CCSR & $-1.5 \%$ & $1.5 \%$ & $-0.1 \%$ & $1.9 \%$ & $-1.9 \%$ \\
\hline PCM & $-2.8 \%$ & $-2.0 \%$ & $2.4 \%$ & $2.1 \%$ & $0.3 \%$ \\
\hline \multicolumn{6}{|l|}{2060} \\
\hline $\mathrm{CCC}$ & $-2.0 \%$ & $-1.7 \%$ & $1.5 \%$ & $3.6 \%$ & $-1.3 \%$ \\
\hline CCSR & $-2.1 \%$ & $5.8 \%$ & $-0.8 \%$ & $-0.8 \%$ & $-2.0 \%$ \\
\hline PCM & $-6.2 \%$ & $4.9 \%$ & $-2.7 \%$ & $7.3 \%$ & $-3.2 \%$ \\
\hline \multicolumn{6}{|l|}{2100} \\
\hline $\mathrm{CCC}$ & $-11.0 \%$ & $8.3 \%$ & $-7.2 \%$ & $15.3 \%$ & $-5.4 \%$ \\
\hline CCSR & $-6.9 \%$ & $3.6 \%$ & $4.1 \%$ & $1.4 \%$ & $-2.2 \%$ \\
\hline PCM & $-3.1 \%$ & $0.2 \%$ & $0.0 \%$ & $4.3 \%$ & $-1.4 \%$ \\
\hline
\end{tabular}

Table 12b: Predicted change in net income per animal from AOGCM climate scenarios for large farms (US\$/animal)

\begin{tabular}{|c|c|c|c|c|c|}
\hline & Beef cattle & Dairy cattle & Goats & Sheep & Chickens \\
\hline Baseline income & 146.01 & 120.18 & 6.04 & 12.08 & 1.68 \\
\hline \multicolumn{6}{|l|}{2020} \\
\hline $\mathrm{CCC}$ & -4.50 & -3.11 & -1.01 & -3.20 & -0.35 \\
\hline CCSR & -14.93 & -4.89 & -0.99 & -3.30 & -0.39 \\
\hline PCM & -7.63 & 23.16 & -0.59 & -1.84 & 0.07 \\
\hline \multicolumn{6}{|l|}{2060} \\
\hline $\mathrm{CCC}$ & -11.50 & 23.35 & -1.01 & -3.35 & -0.03 \\
\hline CCSR & 7.02 & -12.61 & -1.76 & -5.25 & -0.48 \\
\hline PCM & -13.73 & -12.36 & -1.69 & -5.75 & -0.48 \\
\hline \multicolumn{6}{|l|}{2100} \\
\hline $\mathrm{CCC}$ & -20.75 & -46.00 & -2.26 & -8.27 & -1.02 \\
\hline CCSR & 1.40 & 63.36 & 0.23 & 3.43 & -0.28 \\
\hline PCM & -12.67 & 28.40 & -1.23 & -3.22 & -0.08 \\
\hline
\end{tabular}


Table 12c: Predicted change in number of each animal per farm from AOGCM climate scenarios for large farms

\begin{tabular}{|c|c|c|c|c|c|}
\hline \multirow[b]{2}{*}{ Baseline number } & \multirow{2}{*}{$\begin{array}{c}\text { Beef cattle } \\
77.58\end{array}$} & \multirow{2}{*}{$\begin{array}{c}\text { Dairy cattle } \\
35.82\end{array}$} & \multirow{2}{*}{$\begin{array}{l}\text { Goats } \\
23.81\end{array}$} & \multirow{2}{*}{$\begin{array}{l}\text { Sheep } \\
49.40\end{array}$} & \multirow{2}{*}{$\begin{array}{c}\text { Chickens } \\
1907.25\end{array}$} \\
\hline & & & & & \\
\hline \multicolumn{6}{|l|}{2020} \\
\hline $\mathrm{CCC}$ & 1.49 & 1.04 & 5.00 & 0.98 & -57.80 \\
\hline CCSR & -2.16 & 0.91 & 6.01 & 1.82 & -123.32 \\
\hline PCM & -1.18 & -0.92 & 0.00 & -1.24 & -96.66 \\
\hline \multicolumn{6}{|l|}{2060} \\
\hline $\mathrm{CCC}$ & -0.51 & -0.56 & 2.44 & -1.43 & -139.20 \\
\hline CCSR & -3.41 & 1.53 & 6.64 & -0.13 & -184.73 \\
\hline PCM & -1.56 & 1.42 & 11.59 & -1.99 & -141.62 \\
\hline \multicolumn{6}{|l|}{2100} \\
\hline $\mathrm{CCC}$ & -14.18 & 1.17 & 25.53 & -2.69 & -289.22 \\
\hline CCSR & -4.75 & -1.98 & 5.78 & 41.22 & -8.72 \\
\hline PCM & 0.21 & -0.64 & 3.57 & 5.24 & -180.19 \\
\hline
\end{tabular}

Table 12d. Predicted change in expected income from AOGCM climate scenarios for large farms (US\$)

$\begin{array}{ccccc}\begin{array}{c}\text { Mean } \\ \text { (US\$/farm) }\end{array} & \begin{array}{c}\text { Total } \\ \text { (billions US\$) }\end{array} & \text { \% change } & \begin{array}{c}\text { Bootstrap } \\ \text { lower 95 \% }\end{array} & \begin{array}{c}\text { Bootstrap } \\ \text { upper 95\% }\end{array}\end{array}$

Expected income

2020

$\begin{array}{cccccc}\text { CCC } & -779 & -6 & -10.0 \% & -932 & -442 \\ \text { CCSR } & -1000 & -8 & -12.8 \% & -1068 & -703 \\ \text { PCM } & -2817 & -22 & -36.0 \% & -4624 & -2481\end{array}$

2060

$\begin{array}{cccccc}\text { CCC } & -3171 & -24 & -40.5 \% & -5358 & -2926 \\ \text { CCSR } & -1232 & -9 & -15.7 \% & -2084 & -345 \\ \text { PCM } & -2362 & -18 & -30.2 \% & -3431 & -2040\end{array}$

2100

\begin{tabular}{cccccc} 
CCC & -6023 & -46 & $-77.0 \%$ & -8567 & -5732 \\
CCSR & -2685 & -21 & $-34.3 \%$ & -6003 & -2184 \\
PCM & -3382 & -26 & $-43.2 \%$ & -5156 & -2896 \\
\hline
\end{tabular}




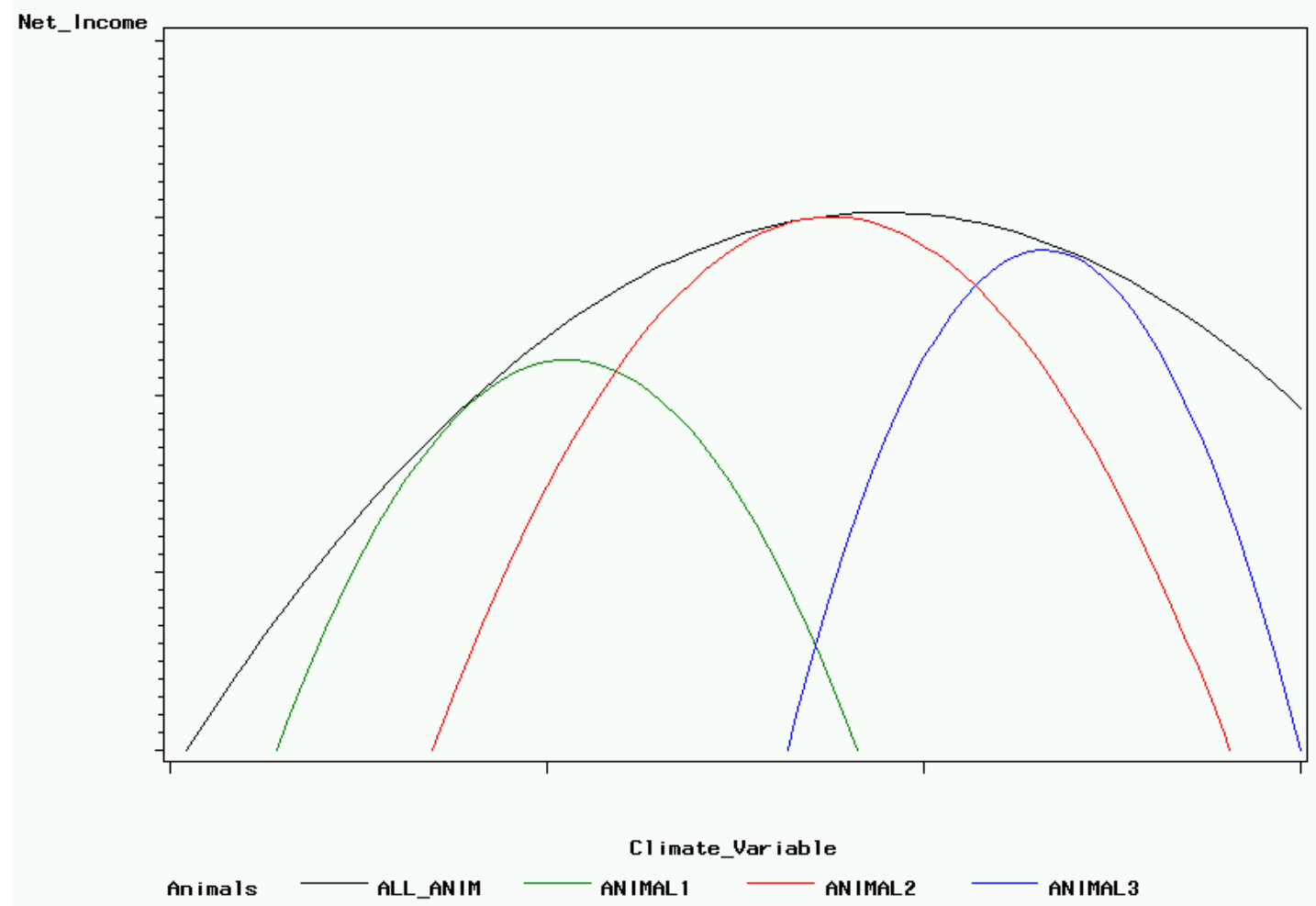

Figure1: Theoretical livestock response functions 


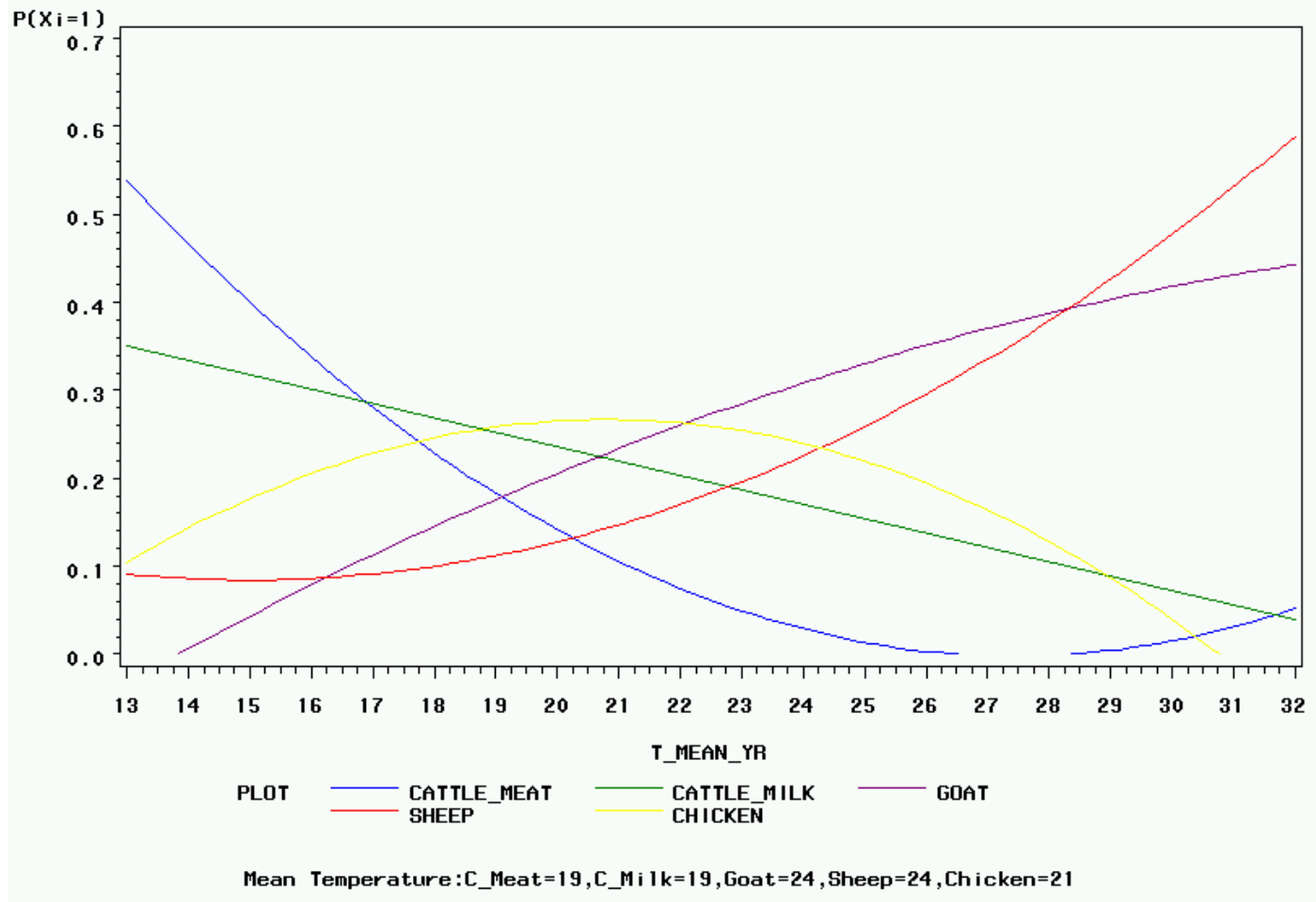

Figure 2a: Estimated probability of selecting species given annual temperature 


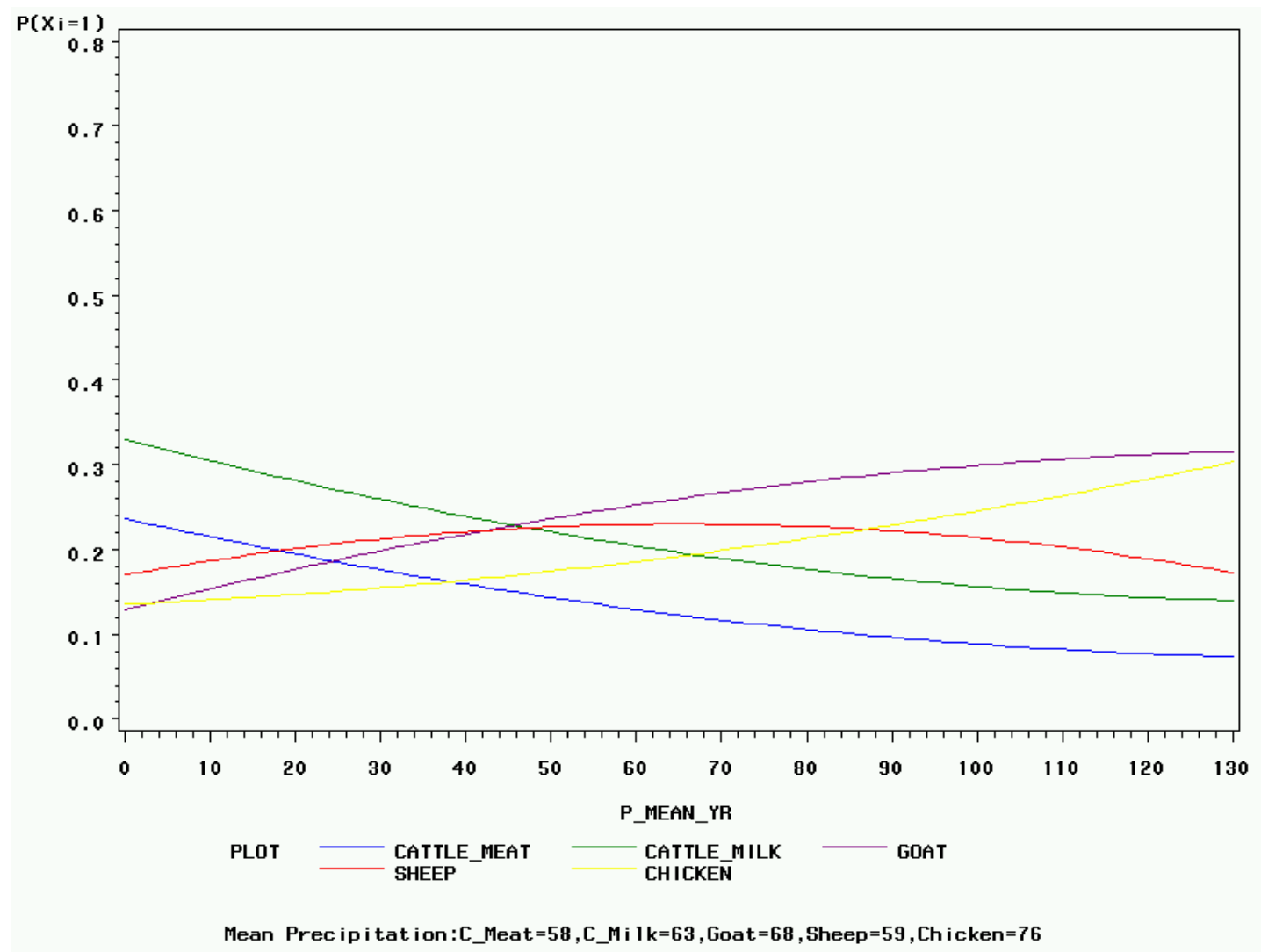

Figure 2b: Estimated probability of selecting species given annual precipitation 


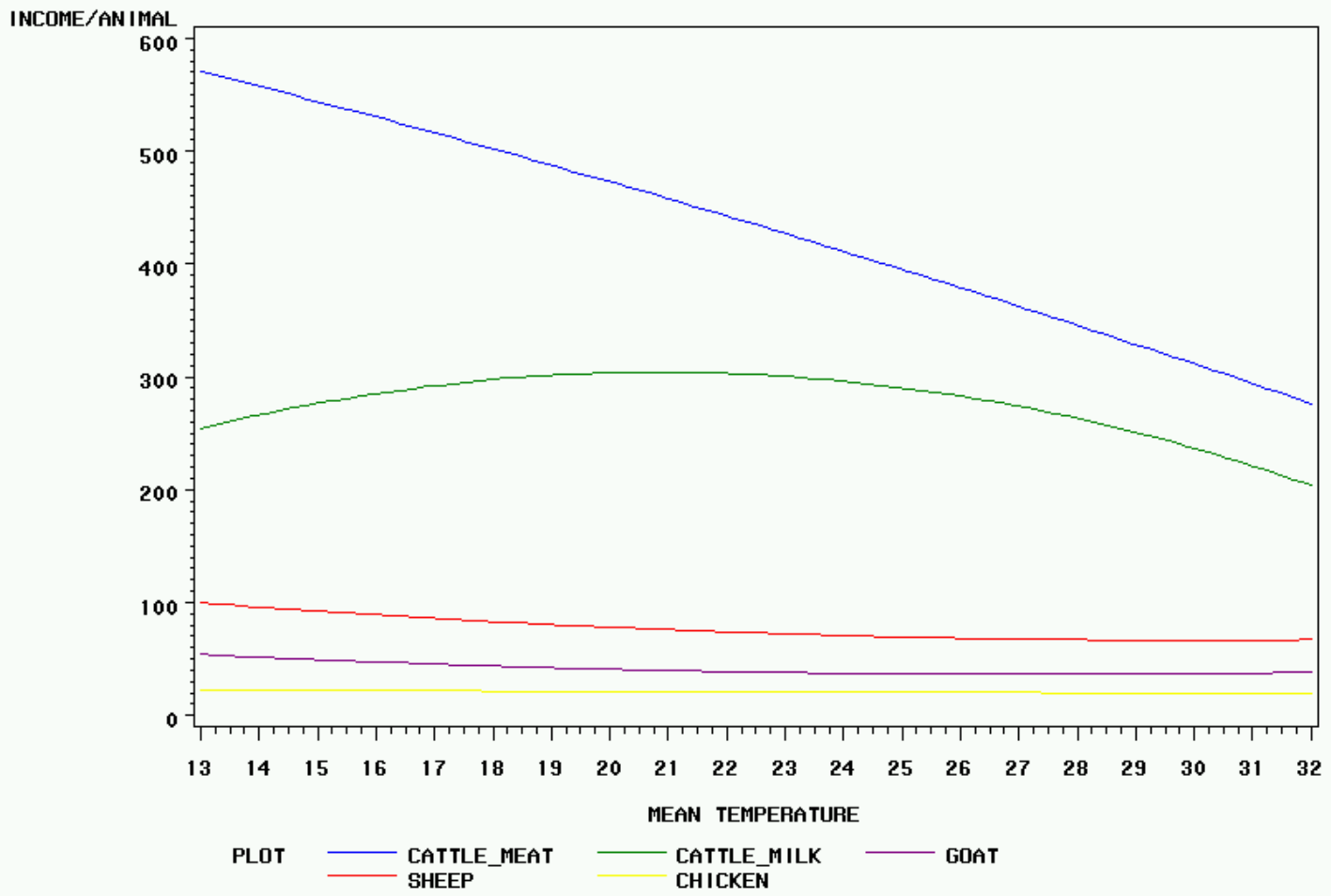

Figure 3a: Net revenue response function to temperature 


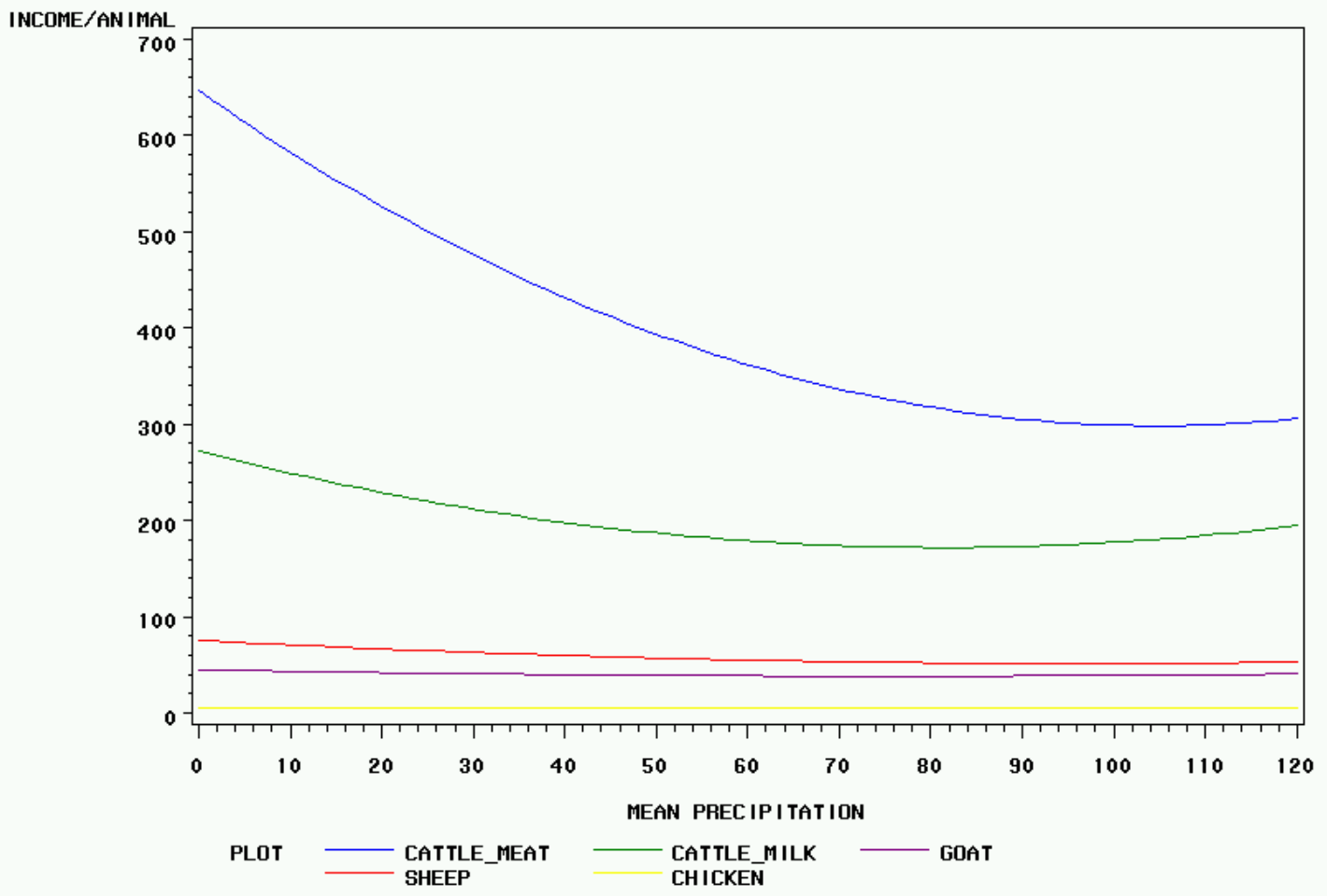

Figure 3b: Net revenue response function to precipitation 


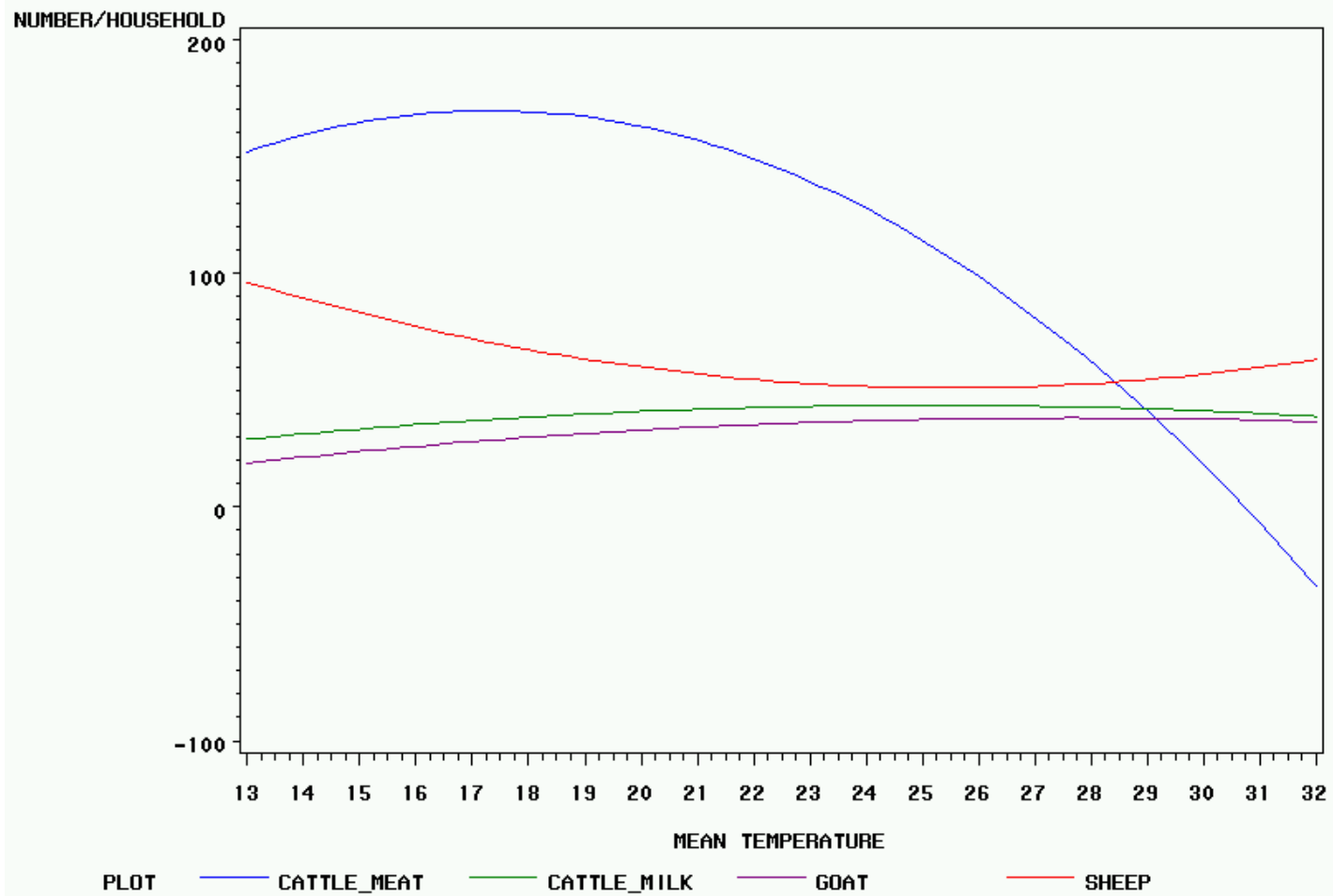

Figure 4a: Number of livestock response function to temperature 


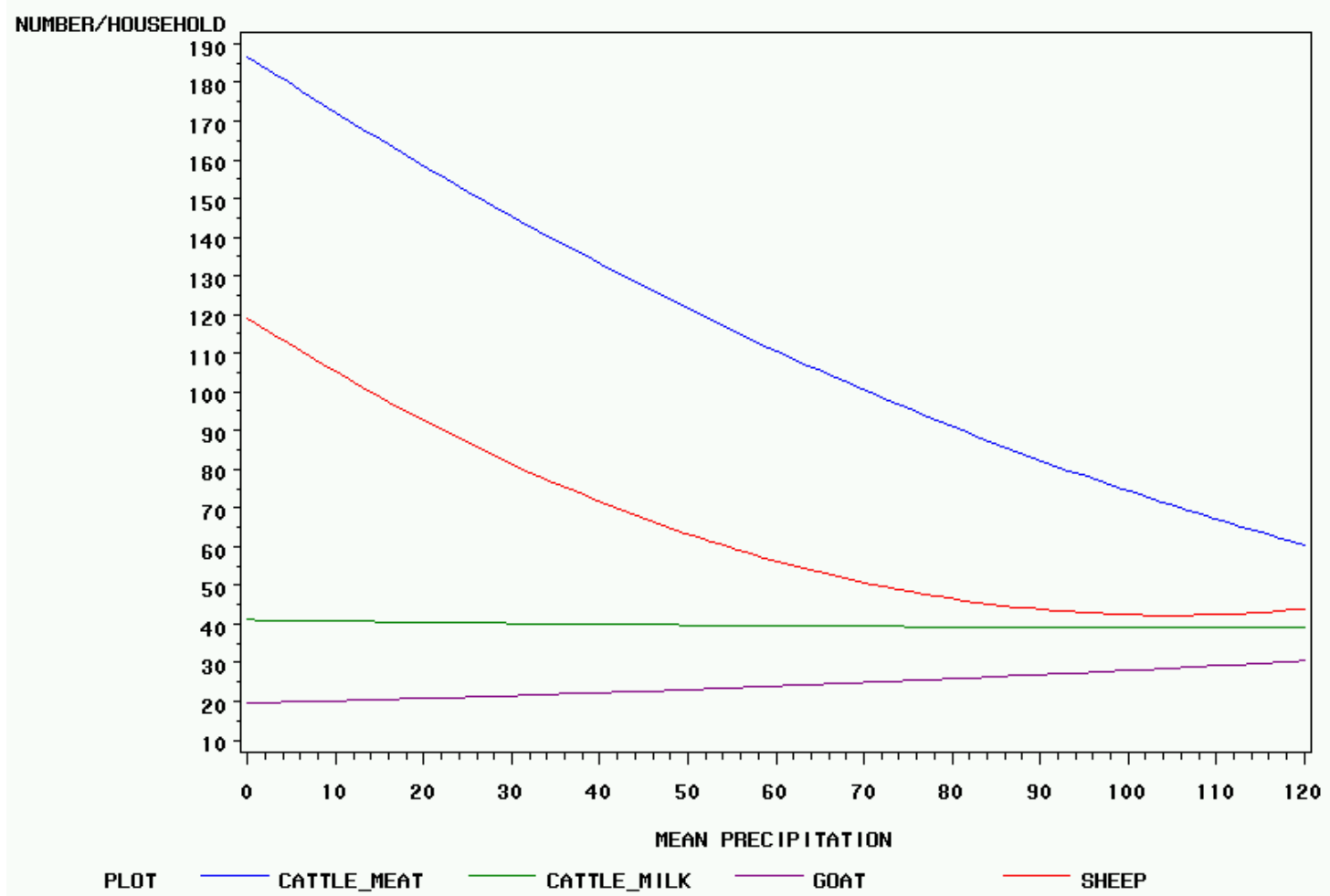

Figure 4b: Number of livestock response function to precipitation 


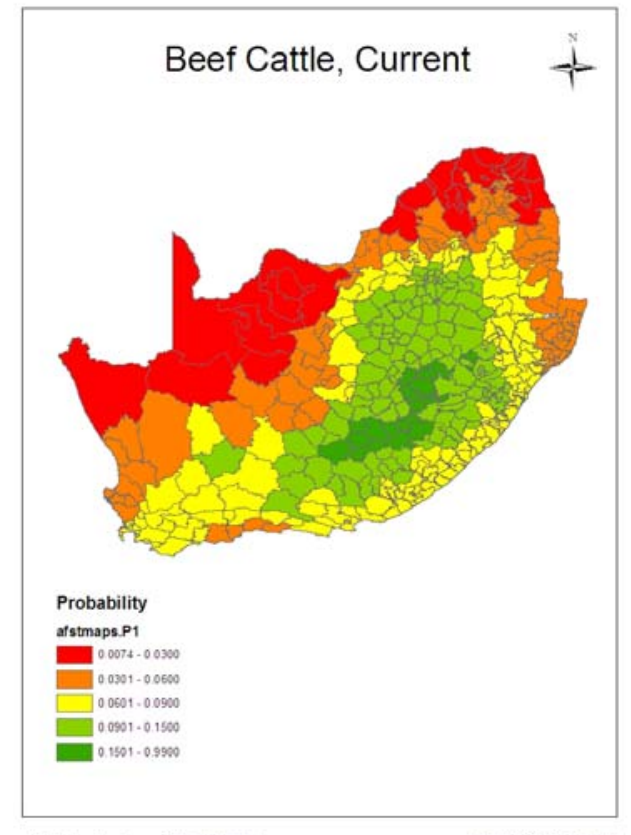

חบ:

HOOOL SEO, YAE UNW

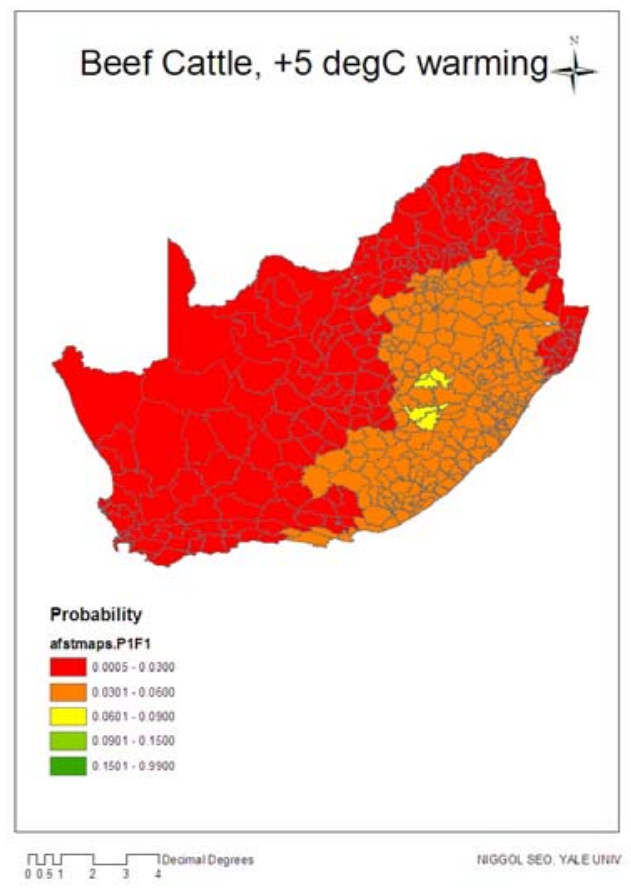

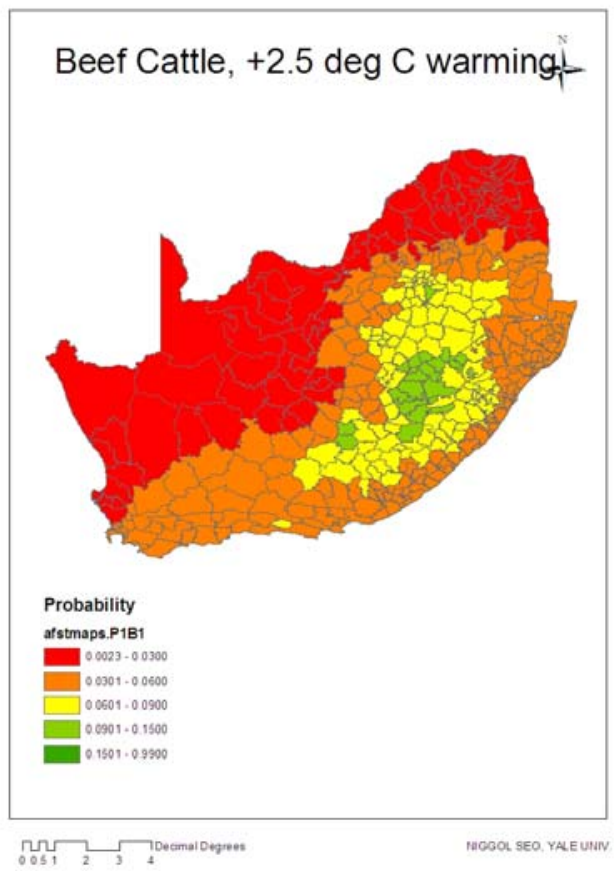

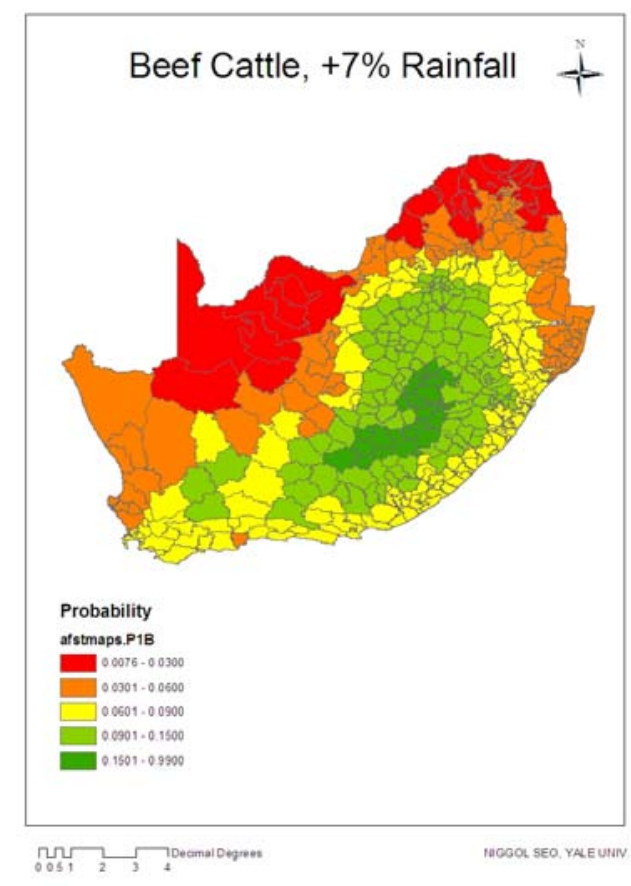

Figure 5: The change in the probability of choosing beef cattle in South Africa with uniform climate change scenarios 

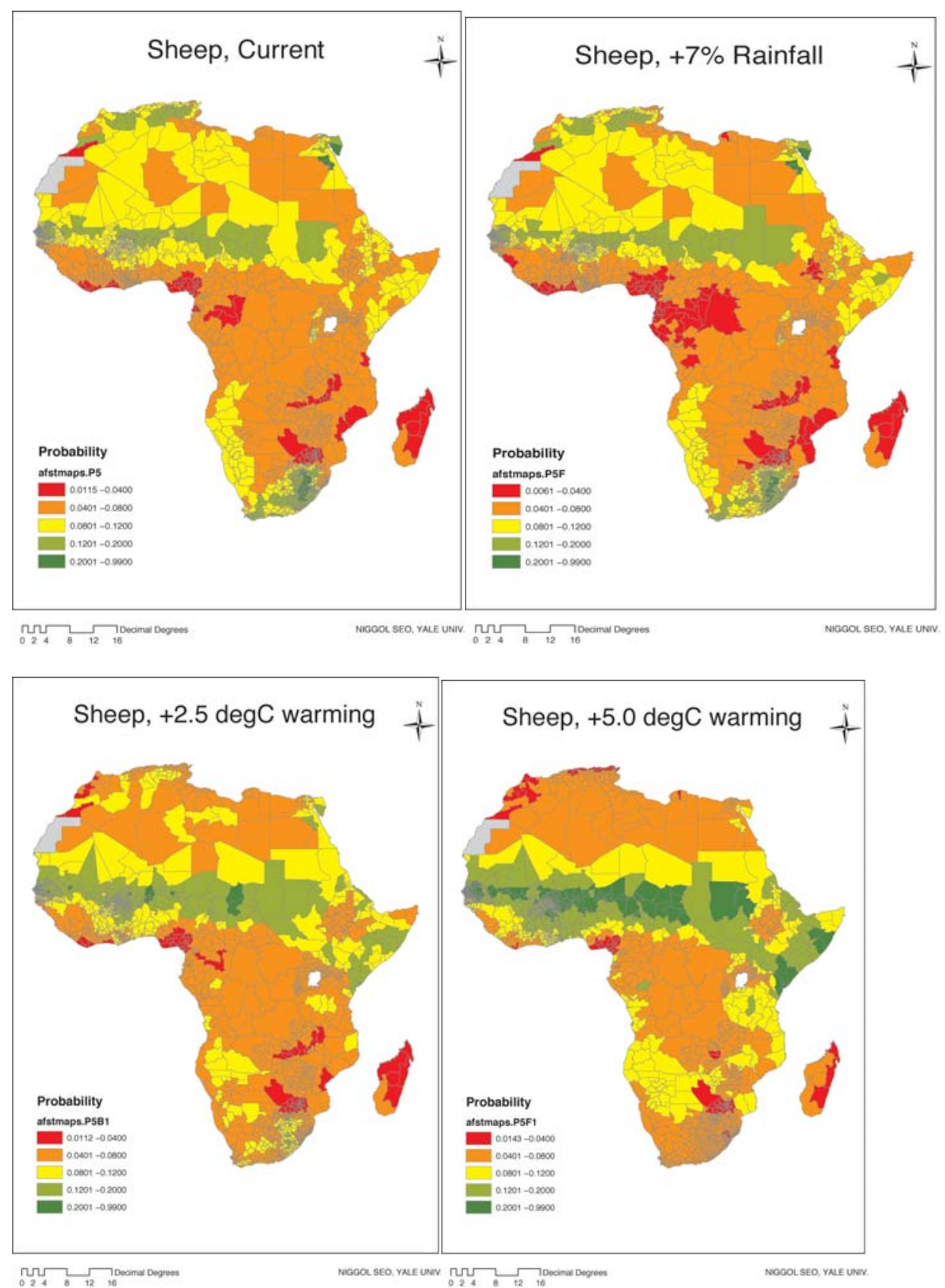

Figure 6: The change in the probability of choosing goats in Africa with uniform climate change scenarios 